\title{
¿HACIA UN MODELO EUROPEO DE TUTELA COLECTIVA?
}

\section{TOWARDS A EUROPEAN SYSTEM OF COLLECTIVE REDRESS?}

\author{
Fernando Gascón InCHAUSTI \\ Catedrático de Derecho Procesal \\ Universidad Complutense de Madrid \\ Instituto de Derecho Europeo e Integración Regional (IDEIR)
}

Recibido: 11.06.2020 / Aceptado: 23.06.2020

DOI: https://doi.org/10.20318/cdt.2020.5672

\begin{abstract}
Resumen: El legislador europeo acaba de aprobar una nueva directiva acerca del ejercicio de acciones de representación para la defensa de los derechos e intereses de los consumidores. El camino recorrido para llegar aquí ha sido arduo y refleja las diversas pulsiones que se enfrentan en esta materia: de un lado, la asunción de que sin herramientas que permitan la tutela colectiva no será posible lograr la plena eficacia del Derecho de consumo; de otro, el temor a que las acciones colectivas «a la europea» se utilicen de forma abusiva y acaben pareciéndose demasiado a las class-actions estadounidenses, con todo lo que llevan asociado. Sobre esta base, se analizan las opciones tomadas en relación con los elementos clave del sistema, como la legitimación, las modalidades de tutela, el acceso a las fuentes de prueba, la eficacia de resoluciones anteriores, las transacciones y la financiación. A pesar de los avances, el legislador europeo está promoviendo una armonización de alcance muy limitado, que permite dudar de la existencia de un genuino modelo europeo de tutela colectiva.
\end{abstract}

Palabras clave: tutela colectiva, acciones colectivas, acciones de representación, legitimación, acciones de cesación, acciones de reparación, financiación de litigios, transacciones colectivas.

\begin{abstract}
The European lawmaker has just approved a new directive on representative actions for the protection of the collective interests of consumers. The road travelled to get here has been arduous and reflects the various drives that are faced in this matter: on the one hand, the assumption that without tools that allow collective redress it will not be possible to achieve the full effectiveness of consumer law; on the other, the fear that European-style collective actions will be used in an abusive way and end up looking too much like American class-actions, with everything associated to them. On this basis, the paper analyses the choices made as to the key elements of the system, such as legal standing, available remedies, access to sources of evidence, the effects of previous final decisions, settlements or funding. Despite the progress, the lawmaker is promoting a very limited harmonization, which casts doubt on the existence of a genuine European model of collective redress.
\end{abstract}

Keywords: collective redress, collective actions, representative actions, legal standing, injunctions, actions for redress, litigation funding, collective settlements.

\footnotetext{
*Este trabajo fue preparado para ser defendido en el Seminario «Hacia un proceso civil convergente con Europa: balance de situación», dirigido por la Prof. Pilar Peiteado Mariscal y por mí mismo, que debería haberse celebrado en la Facultad de Derecho de la UCM el 25 de junio de 2020 y que tuvo que ser suspendido a consecuencia de la pandemia asociada a la Covid-19. Es uno de los resultados del proyecto de investigación "Hacia un proceso civil convergente con Europa. Hitos presentes y retos futuros” (PGC2018-094693-B-I00), financiado por el Ministerio de Ciencia e Innovación.
} 
Sumario: I. La tutela colectiva de los consumidores en la agenda legislativa de la Unión Europea: una trayectoria algo errática desde el Libro Verde de 2005 hasta la Directiva de 2020. 1. Primeras aproximaciones de las instituciones europeas a la tutela colectiva. 2. La Recomendación de la Comisión de 11 de junio de 2013. 3. La Propuesta de Directiva de 11 de abril de 2018 y la Directiva de 30 de junio de 2020. II. Elementos definitorios del nuevo sistema. 1. Armonización de mínimos. 2. Ámbito. A). Ámbito material; B). Ámbito temporal. 3. Legitimación para el ejercicio de las acciones representativas. A) Exigencias diversas en función del carácter nacional o transfronterizo de la acción. B) Los estándares europeos para la atribución de legitimación extraordinaria de cara al ejercicio de acciones colectivas. C) Controles al ejercicio de acciones por las entidades legitimadas. D). Título de legitimación de las entidades habilitadas. 4. Tutelas disponibles: la accionabilidad colectiva. A) Pretensiones de cesación. B) Pretensiones de reparación. $1^{\circ}$. Contenido de la tutela reparatoria; $2^{\circ}$. ¿Opt-in u optout?; $3^{\circ}$. Eficacia de la tutela reparatoria. C). Relaciones entre cesación y reparación. 5. Herramientas procesales para reforzar la eficacia de las acciones representativas. A) Acceso a pruebas. B) Eficacia de resoluciones judiciales y administrativas previas. C) Relación entre procesos conexos. D) ¿Exigencias procedimentales? 6. Transacciones. 7. Financiación y costas. III. A modo de conclusión provisional: ¿puede existir un modelo europeo de tutela colectiva, más allá del rechazo al modelo estadounidense?

\section{La tutela colectiva de los consumidores en la agenda legislativa de la Unión Europea: una tra- yectoria algo errática desde el Libro Verde de 2005 hasta la Directiva de 2020}

\section{Primeras aproximaciones de las instituciones europeas a la tutela colectiva}

1. En el ámbito de la Unión Europea, las cuestiones que suscita la tutela colectiva de los derechos se han vinculado primordialmente al ámbito del consumo. No es este, obviamente, el único sector del ordenamiento para el que las técnicas de tutela colectiva podrían ser adecuadas o incluso necesarias en el plano civil: lo mismo puede decirse del medio ambiente, la defensa de la competencia y la protección de datos personales, por citar algunas materias en relación con las cuales se ha proyectado ya la acción normativa de las instituciones europeas. Los esfuerzos hasta ahora, sin embargo, se han centrado de manera preferente en el ámbito del consumo y este es, sin duda, un factor que no puede ignorarse: aunque sea de forma inconsciente, se piensa habitualmente en consumo cuando se aborda la tutela colectiva de los derechos, tanto en la Unión Europea como en la mayoría de los sistemas nacionales. Por ello, el tratamiento de la tutela colectiva de los derechos se ha desarrollado en la agenda legislativa europea en paralelo a las singularidades asociadas a una adecuada tutela de los derechos de los consumidores.

2. Ofrecer un elevado nivel de protección a los consumidores ha sido, casi desde sus inicios, un objetivo primordial de las instituciones europeas, por razones en las que no hace falta detenerse. La estrecha vinculación entre consumo y mercado interior, además, atribuyó a la Comunidad -primero- y a la Unión -después- competencia para la elaboración normativa en este sector, que se ha traducido en la aprobación de un número muy elevado de directivas y reglamentos. Inicialmente se trataba, sobre todo, de reconocer derechos a consumidores y usuarios frente a empresarios y profesionales, desde un punto de vista sustantivo ${ }^{1}$ : de forma paulatina el legislador europeo ha ido ocupándose así de regular la posición de los consumidores en los más variados sectores de la contratación. El Derecho de consumo en los Estados miembros es, por ello, una parcela del ordenamiento de regulación primordialmente europea, sin perjuicio de desarrollos o refuerzos normativos nacionales.

3. La progresiva construcción del Espacio Europeo de Justicia permitió fijar también la atención en los instrumentos para lograr una tutela eficaz en caso de infracción de los derechos e intereses de los consumidores. En el plano de los litigios individuales - consumidor frente a profesional, o viceversa-, ya el Convenio de Bruselas de 1968 contenía fueros especiales en materia de consumo, que en la práctica

\footnotetext{
${ }^{1}$ Empezando, si se recuerda, por la responsabilidad derivada de productos defectuosos (cfr. Directiva 85/374/CEE del Consejo, de 25 de julio de 1985, relativa a la aproximación de las disposiciones legales, reglamentarias y administrativas de los Estados Miembros en materia de responsabilidad por los daños causados por productos defectuosos, DO L 210 de 7.8.1985).
} 
reconocían a los consumidores el derecho a «litigar en casa», tanto si eran demandantes como si eran demandados. Esta especial línea de protección procesal en los litigios transfronterizos se ha mantenido en instrumentos posteriores (v.g., a la hora de expedir un título ejecutivo europeo o un requerimiento de pago europeo frente a un consumidor). Además, la protección a título individual de los consumidores se ha visto reforzada a través de una apuesta clara de las instituciones europeas por los sistemas de solución alternativa de controversias: tras la directiva sobre ADR de consumo ${ }^{2}$ los Estados miembros están obligados a asegurar la existencia de sistemas de solución extrajudicial de litigios que cumplan unos estándares elevados de calidad. ${ }^{3}$

4. El legislador europeo ha tardado, sin embargo, algo más en ofrecer mecanismos para afrontar de forma integral y eficaz la dimensión colectiva de las infracciones a los derechos de los consumidores. En 1998 se aprobó la directiva sobre acciones de cesación ${ }^{4}$, gracias a la cual los Estados miembros se vieron forzados a introducir en sus ordenamientos acciones cesatorias e inhibitorias frente a conductas lesivas de los derechos de los consumidores. Se trató, sin duda, de un paso significativo, pues este tipo de acciones sirven para dispensar tutela colectiva lato sensu, aunque no siempre tengan incidencia directa en la esfera individual de los sujetos afectados. De hecho, en 2009 el sistema fue objeto de ciertas adaptaciones y mejoras a través de una nueva directiva ${ }^{5}$, aunque se mantuvo la limitación en cuanto al contenido de la tutela que podía dispensarse por esta vía: cesaciones y prohibiciones impuestas a los profesionales en beneficio de los consumidores, pero no prestaciones positivas y concretas a favor de estos.

5. La asignatura pendiente hasta ahora, por ello, ha sido la definición por parte de las instituciones europeas de posibles herramientas que permitan dispensar de forma colectiva tutela judicial a situaciones individualizadas en que se haya producido una lesión a los derechos de un número elevado de personas: se trata, en otros términos, de abrir las puertas al ejercicio de genuinas acciones colectivas de contenido resarcitorio o indemnizatorio.

6. La primera muestra clara de que podría entrar dentro de las intenciones del legislador europeo abordar una regulación de este tipo de pretensiones, de hecho, no se produjo directamente en el ámbito del consumo, sino en un sector singular en que los consumidores pueden verse perjudicados de forma generalizada, como son los daños derivados de infracciones a las normas sobre competencia. En diciembre de 2005 la Comisión hizo público el Libro Verde «Reparación de daños y perjuicios por incumplimiento de las normas comunitarias de defensa de la competencia $»^{6}$. Entre las cuestiones que planteaba la Comisión se hallaba la posibilidad de proteger mediante acciones colectivas los derechos de consumidores y compradores con pequeñas reclamaciones, lo que permitiría «reunir toda una serie de pequeñas indemnizaciones en una demanda, ahorrando así tiempo y dinero» ${ }^{7}$. El trinomio «daños antitrust - tutela de los consumidores - acciones colectivas» se mantiene más adelante, cuando la Comisión avanza en la iniciativa aprobando en abril de 2008 el Libro Blanco «relativo a las acciones de daños y perjuicios por incumplimiento de las normas comunitarias de defensa de la competencia» ${ }^{8}$. La Comisión insiste en advertir del riesgo de que tanto los consumidores individuales como las pequeñas empresas renuncien a reclamar los daños puntuales y de poco valor relativo, con el consiguiente debilitamiento de

\footnotetext{
${ }^{2}$ Directiva 2013/11/UE del Parlamento Europeo y del Consejo de 21 de mayo de 2013 relativa a la resolución alternativa de litigios en materia de consumo y por la que se modifica el Reglamento (CE) no 2006/2004 y la Directiva 2009/22/CE (Directiva sobre resolución alternativa de litigios en materia de consumo) (DO L 165, de 18 de junio de 2015, pp. 63-79).

${ }^{3}$ Sobre esto, por todos, cfr. M.L. Villamarín LóPez, "On minimum standards in Consumer ADR”, en R. CAPONI, F. Gascón InChausti, M. STÜRner (eds.), The Role of Consumer ADR in the Administration of Justice. New Trends in Access to Justice under EU Directive 2013/11, Sellier, Munich, 2015, pp. 131-148.

${ }^{4}$ Directiva 98/27/CE del Parlamento Europeo y del Consejo, de 19 de mayo de 1998, relativa a las acciones de cesación en materia de protección de los intereses de los consumidores (DO L 166, 11.6.1998).

${ }_{5}^{5}$ Directiva 2009/22/CE del Parlamento Europeo y del Consejo, de 23 de abril de 2009, relativa a las acciones de cesación en materia de protección de los intereses de los consumidores (DO L 110, 1.5.2009).

${ }^{6} \operatorname{COM}(2005) 672$ final, de 19 de diciembre de 2005.

${ }^{7}$ Cfr. p. 9 del Documento $\operatorname{COM}(2005) 672$ final.

${ }^{8} \mathrm{COM}(2008) 165$ final, de 2 de abril de 2008.
} 
las normas sobre defensa de la competencia. A su juicio, el remedio pasa por combinar «dos mecanismos complementarios de recurso colectivo», las llamadas «demandas en representación» — entabladas por entidades habilitadas, como asociaciones de consumidores, organismos estatales o asociaciones comerciales, en nombre de víctimas identificadas o identificables-y las «demandas colectivas» o grupales -en las que las víctimas deciden expresamente aunar en una sola sus demandas individuales por los daños sufridos-.${ }^{9}$ Posiblemente ni una ni otra sean genuinas acciones colectivas en el sentido en que dicho término se entiende en ciertos sectores de la doctrina y, desde luego, no encajan en la noción de las class actions del Derecho estadounidense. Pero al sugerir su adecuación como instrumento para un private enforcement más efectivo, la Comisión advierte de dos cosas: que está en la esfera de competencia de las instituciones europeas adoptar medidas normativas en relación con estos mecanismos de tutela colectiva y, sobre todo, que tiene intención de impulsarlos. En relación con esto último, resulta significativo el anuncio que se hace: «Estas sugerencias de acciones de reparación de daños y perjuicios en el ámbito de la defensa de la competencia forman parte de una amplia iniciativa de la Comisión para consolidar mecanismos de recursos colectivos en la UE que pueden seguir desarrollándose en este contexto.» ${ }^{10}$

7. Pocos meses después (todavía en 2008), de hecho, la Comisión cumple con lo anunciado presentando un nuevo Libro Verde «sobre recurso colectivo de los consumidores» ${ }^{11}$ : a partir de ese momento, los caminos de los daños antitrust y de las acciones colectivas se separan a efectos de elaboración normativa.

8. La iniciativa para regular las acciones de daños por infracciones a las normas sobre competencia culminó, como es sabido, con la aprobación de la Directiva 2014/104/UE ${ }^{12}$, sin previsión alguna en relación con la tutela colectiva de los derechos: la propia propuesta inicial formulada por la Comisión en $2013^{13}$ omite cualquier referencia a un posible ejercicio colectivo de los derechos; y el considerando 13 de la Directiva establece una suerte de regla de no interferencia: «La presente Directiva no debe exigir a los Estados miembros que introduzcan mecanismos de recurso colectivo para la aplicación de los artículos 101 y 102 del TFUE.» La razón ofrecida es la conveniencia de abordar los problemas que suscita la litigación colectiva de forma horizontal y homogénea, en vez de sectorial. Y es que, de hecho, el mismo día en que se presentó la propuesta de directiva de acciones de daños -el 11 de junio de 2013- se aprobó también un texto básico, la Recomendación de la Comisión «sobre los principios comunes aplicables a los mecanismos de recurso colectivo de cesación o de indemnización en los Estados miembros en caso de violación de los derechos reconocidos por el Derecho de la Unión». ${ }^{14}$ Esta Recomendación es uno de los hitos más relevantes hasta la fecha, aunque tampoco -como puede intuirse- surgió de forma espontánea.

\section{La Recomendación de la Comisión de 11 de junio de 2013}

9. En 2008, el Libro Verde sobre recurso colectivo de los consumidores, a pesar de presentarse como respuesta horizontal a la cuestión de la tutela colectiva, toma como eje principal para el debate la protección de los consumidores y valora, entre otras posibilidades, la adopción de «una medida comunitaria vinculante o no vinculante para garantizar la existencia de un mecanismo judicial de recurso colectivo en todos los Estados miembros» -en relación con la cual se detectan posibles problemas o dificultades, como la financiación, la legitimación activa, la preferencia por un modelo opt-in u opt-out o el peligro de que se presenten demandas infundadas. ${ }^{15}$

\footnotetext{
${ }^{9}$ Cfr. pp. 4 y 5 del Documento COM(2008) 165 final.

${ }^{10}$ Cfr. p. 5 del Documento COM(2008) 165 final.

${ }^{11} \operatorname{COM}(2008) 794$ final, de 27 de noviembre de 2008.

${ }^{12}$ Directiva 2014/104/UE del Parlamento Europeo y del Consejo, de 26 de noviembre de 2014, relativa a determinadas normas por las que se rigen las acciones por daños en virtud del Derecho nacional, por infracciones del Derecho de la competencia de los Estados miembros y de la Unión Europea (DO L 349, de 5 de diciembre de 2014, pp. 1-19).

${ }_{13}$ Propuesta de Directiva de 11 de junio de 2013 [COM(2013) 404 final].

${ }^{14}$ DO L 201, de 26 de julio de 2013, pp. 60-65.

${ }^{15}$ Cfr. pp. 14-16 del Documento COM(2008) 794 final.
} 
10. El 4 de febrero de 2011 la Comisión Europea lanzó una Consulta Pública con el título «Hacia un planteamiento europeo más coherente del recurso colectivo» ${ }^{16}$ con el objetivo de recabar perspectivas y opiniones adicionales. A ello le siguió, un año más tarde, la Resolución del Parlamento Europeo, de 2 de febrero de 2012, «Hacia un planteamiento europeo coherente del recurso colectivo» ${ }^{17}$, que sustancialmente refrendaba la labor desarrollada por la Comisión hasta entonces e instaba a la aprobación de normas vinculantes y de carácter horizontal que permitieran un reforzamiento de la tutela en sectores como el consumo.

11. La aprobación de la Recomendación de 11 de junio de 2013 -simultánea, recuérdese, a la de la propuesta de directiva sobre reparación de daños por conductas contrarias a las normas de competencia- tiene varias posibles lecturas. Se presenta, de un lado, para demostrar que la Unión Europea no ha abandonado la cuestión de la tutela colectiva de ciertos derechos, a pesar de no haber podido llegar a un punto de iniciativa legislativa similar al alcanzado respecto de las acciones de daños por infracciones a las normas sobre competencia. Y, en esa misma medida, supone la asunción de que, al menos por el momento, resulta preferible optar por un instrumento no vinculante para los Estados miembros. La elección de una herramienta de soft-law permite también a la Comisión presentar un modelo relativamente claro de tutela colectiva de los derechos, que pivota sobre dos ejes: el «recurso colectivo de cesación» y el «recurso colectivo de indemnización». ${ }^{18}$ En cuanto a lo primero, la Recomendación es más bien conservadora y reitera las opciones de política legislativa que ya subyacen a la Directiva de 2009, al tiempo que insiste en la necesidad de arbitrar un sistema de medidas cautelares que permitan con rapidez evitar perjuicios irreparables, así como en el deber de los Estados miembros de establecer sanciones adecuadas que aseguren la efectividad de las órdenes de cesación. ${ }^{19}$ Lo realmente innovador de la Recomendación es, por supuesto, lo relativo al sistema de tutela colectiva resarcitoria o indemnizatoria. Y en esto, el enfoque de la Comisión es bastante directo: en el texto de 2013 resulta posible identificar algunas policies claras, agrupadas en torno a un rechazo poco disimulado de todo lo que pudiera evocar una adopción en suelo europeo de las class-actions estadounidenses ${ }^{20}$ Por ello, la Comisión recomienda a los Estados miembros que se decanten por establecer un sistema opt-in o de participación voluntaria ${ }^{21}$, al tiempo que les insta a establecer normas en materia de fijación de honorarios que no incentiven este tipo de litigios ${ }^{22}$, a prohibir los llamados «daños punitivos» ${ }^{23} \mathrm{y}$ a establecer límites y controles a la financiación por terceros. ${ }^{24}$

${ }^{16}$ Documento SEC/2011/0173 FIN.

17 2011/2089(INI).

${ }^{18}$ Cfr., entre otros, Statement of the European Law Institute on Collective Redress and Competition Damages Claims (2014), esp. pp. 11-60 (accesible en https://www.europeanlawinstitute.eu/fileadmin/user_upload/p_eli/Publications/S-5-2014_ Statement_on_Collective_Redress_and_Competition_Damages_Claims.pdf); E. SILVESTRI, "Towards a common framework of Collective Redress in Europe? An Update of the latest Initiatives of the European Commission", Russian Law Journal, 1, 2013, pp. 46-56; A. Montesinos García, «Últimas tendencias en la Unión Europea sobre las acciones colectivas de consumo. La posible introducción de fórmulas ADR», REDUR 12, diciembre 2014, pp. 87-112 (accesible también en https://www.unirioja. es/dptos/dd/redur/numero12/montesinos.pdf); S. CoROMINAS BACH, "Hacia una futura regulación de las acciones colectivas en la Unión Europea (la Recomendación de 11 de junio de 2013)", Revista General de Derecho Europeo, 34 (octubre 2014), pp. 1-30; A. Planchadell Gargallo, "Los retos de Europa ante la litigación colectiva", en I. Díez-Picazo Giménez, J. Vegas ToRRES (coords.), Derecho, Justicia, Universidad. Liber amicorum de Andrés de la Oliva Santos, Ramón Areces, Madrid, 2016, Vol. II, pp. 2615-2633.

${ }^{19}$ Cfr. los apartados 19 y 20 de la Recomendación.

${ }^{20}$ La Recomendación, no obstante, también fue recibida con críticas: cfr. A. STADLER, "Die Vorschläge der Europäischen Kommission zum kollektiven Rechtsschutz in Europa - der Abschied von einem kohärenten europäischen Lösungsansatz?", Zeitschrift für das Privatrecht der Europäischen Union, 2013-5, pp. 281-292; C.I. NAGY, "The European Collective Redress Debate after the European Commission's Recommendation: One Step Forward, Two Steps Back?", Maastricht journal of European and comparative law, 2015-4, pp 530-552; C. MeLleR-HANNICH, "Kollektiver Rechtsschutz in Europa und Europäischer Kollektiver Rechtsschutz”, Zeitschrift für das Privatrecht der Europäischen Union, 2014-2, pp. 92-98; G. BARKER, B.P. FreYens, "The economics of the European Commission's recommendation on collective redress", en E. LeIn, D. FAIRGRIEVE, M. Otero Crespo, V. SMith (eds.), Collective redress in Europe: why and how?, British Institute of International and Comparative Law, 2015, pp. 5-30.

${ }^{21}$ Cfr. los apartados 21 a 24 de la Recomendación.

${ }^{22}$ Cfr. los apartados 29 y 30 de la Recomendación.

${ }^{23}$ Cfr. el apartado 31 de la Recomendación.

${ }^{24}$ Cfr. los apartados 14 a 16 y 32 de la Recomendación. 
12. A pesar del margen de flexibilidad que ofrecía a los Estados miembros, lo cierto es que la Recomendación de 2013 no produjo los efectos deseados. Tanto antes como después de su publicación los Estados miembros desarrollaron sus propias políticas en materia de acciones colectivas resarcitorias sin tener especialmente en cuenta las propuestas procedentes de la Unión Europea. El panorama, por ello, distaba mucho de ser homogéneo en cuestiones básicas, como la legitimación activa, la dicotomía opt-in/opt-out, el control judicial sobre el ejercicio de la acción y los efectos de una eventual resolución o acuerdo transaccional que ponga fin al litigio; ni siquiera todos disponían de un sistema de acciones colectivas que cubriera los mínimos recomendados por la Comisión. ${ }^{25}$

\section{La Propuesta de Directiva de 11 de abril de 2018 y la Directiva de 30 de junio de 2020}

13. Esta situación, sin duda, ha incitado a la Comisión a dar un paso adelante y adentrarse en la senda de la aproximación de legislaciones y de la armonización forzosa, impulsando la elaboración de una directiva sobre acciones colectivas. En concreto, el 11 de abril de 2018 la Comisión Europea lanzó el New Deal for Consumers ${ }^{26}$, un paquete de medidas e iniciativas destinadas a reforzar desde ángulos muy diversos la protección de los consumidores. Y dentro de este marco general se incluía una Propuesta de Directiva relativa a las acciones de representación para la protección de los intereses colectivos de los consumidores $^{27}$. De nuevo, pues, el propósito de abordar la tutela colectiva de forma horizontal se acaba traduciendo, en la práctica, en centrar la atención en el ámbito del consumo, aunque, como se verá seguidamente, el iter legislativo ha conducido a la expansión de la norma al ámbito de la protección de datos. Y es que, como sucede habitualmente, existen notables diferencias entre la propuesta inicial de la Comisión y el texto que ha acabado aprobándose dos años después. El 26 de marzo de 2019 el Parlamento Europeo presentó su informe ${ }^{28}$, con una serie de modificaciones de relevancia. El Consejo, por su parte, aprobó el 28 de noviembre de 2019 su posición común ${ }^{29}$ en la que, como era de esperar, discrepaba del Parlamento y de la Comisión en aspectos de cierta trascendencia. La crisis generada por la pandemia de la Covid-19 demoró la tramitación, que pudo culminar el 30 de junio de 2020 con la aprobación de la Directiva. ${ }^{30}$

14. Como se verá seguidamente, la directiva aprobada tiene un contenido primordialmente procesal, aunque también se adentra en el terreno del derecho sustantivo (v.g., al definir el contenido de las acciones o al afectar a las normas sobre prescripción). Su base jurídica, sin embargo, no se halla en el art.

\footnotetext{
${ }^{25}$ Así se desprende del Informe sobre la aplicación de la Recomendación publicado por la Comisión el 25 de enero de 2018 [Informe de la Comisión al Parlamento Europeo, al Consejo y al Comité Económico y Social Europeo sobre la aplicación de la Recomendación de la Comisión, de 11 de junio de 2013, sobre los principios comunes aplicables a los mecanismos de recurso colectivo de cesación o de indemnización en los Estados miembros en caso de violación de los derechos reconocidos por el Derecho de la Unión (2013/396/UE), COM(2018) 40 final). Para una visión comparada, en doctrina, cfr. V. HARsÁGI / C.H. vAN RHEE (eds.), Multi-party redress mechanisms in Europe: squeaking mice?, Intersentia, Cambridge, 2014; A. Planchadell Gargallo, Las "acciones colectivas" en el ordenamiento jurídico español. Un estudio comparado, Tirant lo Blanch, Valencia, 2014, pp. 345-497.

${ }^{26}$ Para la «presentación en sociedad» de este «nuevo acuerdo», cfr. la nota de prensa elaborada por la propia Comisión: http://europa.eu/rapid/press-release_IP-18-3041_es.htm.

${ }^{27}$ Propuesta de Directiva del Parlamento Europeo y del Consejo relativa a las acciones de representación para la protección de los intereses colectivos de los consumidores y por la que se deroga la Directiva 2009/22/CE [COM/2018/184 final - 2018/0089 (COD)], accesible en https://eur-lex.europa.eu/legal-content/ES/TXT/?qid=1523948214440\&uri=CELEX:52018 PC0184. Para una primera aproximación a su contenido, cfr. A. MonTESINOs GARCíA, "La propuesta de directiva para la tutela colectiva de los consumidores en la Unión Europea", Actualidad civil, 2018-9; J. MARTíN PASTOR, "La tutela de los intereses colectivos de los consumidores en España y en la Unión Europea: de las acciones colectivas de cesación a las acciones representativas de cesación y reparación”, en T. Armenta Deu, S. Pereira Puigvert (coords.), Acciones colectivas (cuestiones actuales y perspectivas de futuro), Marcial Pons, Madrid-Barcelona-Buenos Aires-Sao Paulo, 2018, pp. 93-120.

${ }^{28}$ Resolución legislativa del Parlamento Europeo, de 26 de marzo de 2019, sobre la propuesta de Directiva del Parlamento Europeo y del Consejo relativa a las acciones de representación para la protección de los intereses colectivos de los consumidores y por la que se deroga la Directiva 2009/22/CE (COM(2018)0184 - C8-0149/2018 - 2018/0089(COD))

${ }^{29} \mathrm{https}$ ://eur-lex.europa.eu/legal-content/ES/TXT/PDF/?uri=CONSIL:ST_14600_2019_INIT\&from=EN

${ }^{30}$ El texto aprobado, en versión inglesa y pendiente de revisión lingüística y ajustes formales, está disponible en https:// www.consilium.europa.eu//media/44766/st09223-en20.pdf?utm_source=dsms-auto\&utm_medium=email\&utm_campaign=E $\mathrm{U}+$ consumers+obtain+access+to+collective+redress.
} 
81.2 TFUE -que abre las puertas a una cierta armonización procesal en pos de la tutela judicial efectiva y el buen funcionamiento de los procesos civiles, como condiciones para mejorar la litigación transfronteriza-, sino que la nueva directiva se sostiene sobre el art. 169 TFUE, que obliga a la Unión a reforzar la protección de los consumidores y, en consecuencia, sobre el art. 114 TFUE, que permite la aproximación de las legislaciones de los Estados miembros cuando tenga por objeto el establecimiento y el funcionamiento del mercado interior. La amplitud del art. 114 TFUE permite una armonización más extensa, no ceñida necesariamente a los litigios con dimensión transfronteriza -que es el límite que se impone a las disposiciones que se adopten para la construcción del Espacio Europeo de Justicia en materia civil.

15. A pesar de las puertas que permite abrir el art. 114 TFUE, se advierte una clara divergencia de enfoques en relación con el alcance armonizador entre la Propuesta inicial de la Comisión -refrendada en esto por el Parlamento- y la posición tomada por el Consejo, finalmente aceptada después. La Comisión y el Parlamento eran partidarios de establecer un régimen común -bastante escuálido, eso sí- para el ejercicio de acciones representativas, acompañado de algunas especialidades en asuntos transfronterizos. Para el Consejo, en cambio, la mayor aproximación de legislaciones debía darse sobre todo respecto del ejercicio de acciones colectivas transfronterizas, mientras que cuando estas tengan un alcance puramente nacional o doméstico la incidencia de la directiva sobre el ordenamiento interno debería reducirse significativamente. Subyacían, en este punto como en otros, dos visiones muy diferentes en las instituciones europeas: el Parlamento, más atento a la tutela de los consumidores, se mostraba generoso a la hora de legitimar la inmisión de la Unión Europea en la autonomía procesal de los Estados miembros; el Consejo, en cambio, se decantó claramente por esta última y trasladó al debate político -y, en lo que importa, al texto definitivo- la visión de varios Estados miembros, claramente reacios a la generalización de sistemas de tutela colectiva resarcitoria y a la propagación a suelo europeo de algo que pueda asemejarse a las class actions estadounidenses. ${ }^{31}$

16. Esta prevención hacia cuanto suene a class action ha sido recurrente desde las primeras aproximaciones de las instituciones europeas a esta materia: tan relevante ha sido determinar los puntos necesitados de tratamiento como evitar cualquier riesgo de litigación abusiva y de instrumentalización de la tutela colectiva para distorsionar el mercado. ${ }^{32}$ La muestra más clara de esa voluntad de definir la European way to collective redress es que se evitan abiertamente expresiones «sospechosas», como «acciones colectivas» o «acciones de clase», y se ha optado por unos términos mucho más asépticos, «acciones de representación», a pesar de su carácter equívoco -como se verá, el sistema no descansa necesariamente en una noción técnica de representación.

\section{Elementos definitorios del nuevo sistema}

17. Un análisis de lo que la nueva directiva regula y de aquello que omite regular permite identificar los elementos definitorios del sistema europeo de acciones representativas que se acaba de aprobar.

\section{Armonización de mínimos}

18. En términos generales, debe señalarse que el texto aprobado no contiene una propuesta más o menos acabada o completa de proceso colectivo para la tutela de los consumidores, esto es, una suerte de «proceso colectivo europeo», equivalente al proceso europeo de escasa cuantía o al proceso

\footnotetext{
${ }^{31}$ La literatura jurídica estadounidense sobre la materia es totalmente inabarcable. Para una excelente aproximación desde el ordenamiento español, cfr. J. LóPEz SÁnchez, El sistema de las “class actions" en los Estados Unidos de América, Comares, Granada, 2011.

${ }^{32}$ Cfr. A. Muñoz Aranguren, La litigación abusiva: delimitación, análisis y remedios, Marcial Pons, Madrid-BarcelonaBuenos Aires-Sao Paulo, 2018, pp. 95 y ss.
} 
monitorio europeo. Diversamente, la directiva se limita a abordar aspectos diversos de la tutela colectiva de los consumidores, como la determinación de las entidades habilitadas para el ejercicio de acciones representativas en otros Estados miembros y las clases de tutela colectiva que se pueden solicitar de los tribunales $-\mathrm{o}$, en algunos países, de las autoridades administrativas-: en este punto lo novedoso es, sin duda, la inclusión de las medidas de reparación, que habían quedado al margen de las acciones normativas anteriores del legislador europeo (las directivas sobre acciones de cesación de 1998 y de 2009). También se incluyen previsiones destinadas a conocer y controlar la financiación con que cuenten las entidades habilitadas, los requisitos para la aceptación de transacciones colectivas, el deber del empresario de informar a los consumidores del resultado del proceso colectivo o la suspensión del plazo de prescripción de la acción de reparación del consumidor individual mientras se tramite una acción colectiva. Pero no se desprende del texto aprobado un mínimo esbozo de estructura procedimental común, ni «piezas procesales» homogéneas [(como podría ser, v.g., un control judicial inicial para el ejercicio de la acción colectiva, al estilo de la class certification order de la regla 23(c)(1) de las Federal Rules of Civil Procedure estadounidenses]: la autonomía procesal de los Estados miembros seguirá siendo en este punto prevalente. ${ }^{33}$

19. De hecho, como se irá viendo, algunas de las previsiones más «atrevidas» se presentan como facultativas para los Estados miembros, de modo que la directiva, en algunos aspectos de importancia, ha acabado pareciéndose a una recomendación, pues no determina necesariamente implementaciones a nivel nacional.

20. En esta línea, el art. 1.2 establece con claridad que los Estados miembros podrán adoptar o mantener otros instrumentos procesales para proteger los intereses colectivos de los consumidores a escala nacional. El precepto, además, se ocupa de aclarar el impacto armonizador de la directiva: si en un Estado miembro existen varios medios para promover la tutela colectiva de los consumidores, al menos uno de ellos habrá de cumplir con las exigencias establecidas en ella. En consecuencia, en aquellos ordenamientos en que solo exista un sistema de tutela colectiva y en aquellos en que aún no exista ninguno, el impacto de la nueva normativa europea será más relevante y los estándares europeos deducibles de la directiva se convertirán también en nacionales. Allí donde existan varias herramientas, en cambio, se producirá una suerte de competencia entre ellas, que acabará resolviéndose a favor de aquella que sea percibida como más eficiente por los operadores jurídicos facultados para utilizarlas.

21. Debe reconocerse, en definitiva, que el nivel de armonización al que se aspira resulta un tanto decepcionante: las instituciones europeas parecen haber asumido que los diversos sistemas -muy heterogéneos entre sí- ya adoptados en la mayoría de los Estados miembros tienen que poder mantenerse. Por eso, el legislador europeo, más modestamente, aspira a obligar a que en todos ellos exista un sistema de tutela colectiva que permita obtener el resarcimiento de los daños -algo, sin duda, valioso-, a que resulte posible un ejercicio transfronterizo de acciones colectivas por entidades representativas de otros Estados miembros y a que se establezcan ciertos controles sobre su financiación.

\section{2. Ámbito}

\section{A) Ámbito material}

22. La nueva directiva aspira a establecer un ámbito de aplicación material muy amplio: las acciones de representación previstas han de permitir reaccionar frente a cualesquiera infracciones cometidas por comerciantes que perjudiquen o puedan perjudicar los intereses colectivos de los consumidores en cualquiera de los sectores sobre los que se haya proyectado la actividad normativa de las instituciones

\footnotetext{
${ }^{33}$ El considerando 12 no podría ser más rotundo: "In line with the principle of procedural autonomy, this Directive should not contain provisions on all aspects of proceedings in representative actions".
} 
europeas (art. 2.1). La tutela colectiva de corte europeo, por tanto, se centra en el ámbito del consumo, entendido en un sentido muy flexible, en el que también se incluye la protección de datos personales.

23. En la versión inicialmente presentada por la Comisión -avalada y ligeramente aumentada por el Parlamento-, los concretos sectores del Derecho de consumo sobre los que podría proyectarse la tutela colectivo-representativa se determinaban en el Anexo I, en el que por orden cronológico de promulgación se enumeraban sesenta y cinco directivas y reglamentos. La posición común del Consejo mantuvo esta técnica de remisión al Anexo I, como forma de hacer más adaptable la directiva a desarrollos normativos posteriores, pero propuso una mejora evidente, que se ha mantenido en el texto definitivo: organizar el listado de directivas y reglamentos de forma sistemática, identificando parcelas o sectores del Derecho de consumo europeo - $\mathrm{u}$ otras que, sin pertenecer tal vez al ámbito del consumo stricto sensu, también se han de beneficiar de la existencia de una herramienta de tutela colectiva.

24. En primer término, se hace referencia a una suerte de «Parte General» del Derecho europeo de consumo, bajo la rúbrica «A. Legislación general de protección del consumidor», en la que se incluyen la responsabilidad por los daños causados por productos defectuosos, ${ }^{34}$ las cláusulas abusivas en los contratos celebrados con consumidores, la venta y las garantías de los bienes de consumo, los contratos de suministro de contenidos y servicios digitales, la seguridad general de los productos, las prácticas comerciales desleales de las empresas en sus relaciones con los consumidores, la publicidad engañosa y comparativa, así como el bloqueo geográfico injustificado y otras formas de discriminación por razón de la nacionalidad, del lugar de residencia o del lugar de establecimiento de los clientes en el mercado interior. A partir de aquí, se incluye lo que podría ser la «Parte Especial», en la que se distinguen los siguientes sectores: (B) Información sobre los productos y etiquetado de los productos; (C) Derechos de los pasajeros; (D) Turismo (incluidos los contratos de aprovechamiento por turno de bienes de uso turístico, la adquisición de productos vacacionales de larga duración y los viajes combinados); (E) Sanidad (medicamentos para uso humano y productos cosméticos); (F) Comercio electrónico y servicios por vía electrónica; (G) Telecomunicaciones; (H) Datos personales; ${ }^{35}$ (I) Mercado de la energía; (J) Eficiencia energética; (K) Resolución de litigios (ADR de consumo y resolución de litigios en línea en materia de consumo); (L) Servicios financieros generales; (M) Servicios de inversión; y (N) Servicios de seguros y prestaciones de jubilación.

25. Se recordará, por otra parte, que la razón por la que los instrumentos de tutela colectiva desaparecieron de las iniciativas y de la posterior regulación de la UE en materia de daños antitrust fue la voluntad de ofrecer un enfoque horizontal y general a estas herramientas procesales ${ }^{36}$. En vista del contenido del Anexo I, resulta paradójico comprobar cómo, al final de todo el camino, las acciones de daños derivados de infracciones de la competencia han quedado al margen de la actuación legislativa europea: si se admiten acciones colectivas para la reclamación de los daños padecidos por los consumidores a resultas de conductas contrarias a las normas sobre defensa de la competencia será por voluntad del legislador nacional, pero no por exigencia de la Unión. ${ }^{37}$ Y, por supuesto, también queda fuera el

\footnotetext{
${ }^{34}$ Apunta LÓPEZ SÁNCHEZ con acierto que en este ámbito no es sencillo hablar de "prácticas lesivas del Derecho de la Unión" -que es la expresión usada en la directiva-, sino más bien de "responsabilidad del fabricante en razón del carácter defectuoso del producto distribuido" (J. LóPEZ SÁnChEZ, "La Propuesta de directiva sobre acciones de representación para la protección de los intereses colectivos de los consumidores y el ámbito de representación de las entidades habilitadas para su ejercicio", en F. Jiménez Conde (dir.), Olga Fuentes Soriano, Isabel González Cano (coords.), Adaptación del Derecho Procesal español a la normativa europea y a su interpretación por los tribunales, Tirant lo Blanch, Valencia 2018, pp. 413-421, en p. 417).

${ }^{35}$ En relación con la tutela colectiva frente a las infracciones a la normativa sobre protección de datos, cfr. A. PAто, "The Collective Private Enforcement of Data Protection Rights”, en L. Cadiet, B. Hess, M. Requejo Isidro, Privatizing Dispute Resolution. Trends and Limits, Nomos, Baden-Baden, 2019, pp. 131-154; también M. ReQuejo Isidro, "La aplicación privada del derecho para la protección de las personas físicas en materia de tratamiento de datos personales en el Reglamento (UE) 2016/679", La Ley Mercantil, № 42 (diciembre 2017)

${ }^{36}$ Cfr. supra, núm. 6.

${ }^{37}$ Cfr. G. BÁnd, P. Darák, P. LÁncos, T, Tóth (eds.): Private Enforcement and Collective Redress in European Competition Law (2016 FIDE Congress), Wolters Kluwer, Budapest, 2016; F. WeBER, “'A chain reaction' or the necessity of collective actions for consumers in cartel cases”, Maastricht journal of European and comparative law, 2018-2, pp. 208-230.
} 
sector del medio ambiente, a pesar de tratarse de una materia sobre la que la Unión ejerce competencias y en relación con la cual podrían tener cabida acciones civiles de alcance colectivo. ${ }^{38}$

\section{B) Ámbito temporal}

26. En cuanto al ámbito temporal de aplicación del sistema, la propuesta inicial de la Comisión, avalada por el informe del Parlamento Europeo, pretendía ceñirlo a las infracciones cometidas después de su entrada en vigor. El texto definitivo, siguiendo la posición del Consejo, plantea en esto un enfoque más beneficioso para los consumidores: se han de aplicar las nuevas reglas a las acciones representativas ejercitadas con posterioridad a su fecha de aplicación, con independencia del momento en que se produjo la infracción (art. 25.1). Se evitan, con ello, las indudables dificultades de interpretación y aplicación que derivarían de la propuesta inicial, pues no siempre será posible identificar la fecha de una infracción, especialmente si se prolonga en el tiempo; y ello, a su vez, provocaría dudas en cuanto al tipo y al contenido de la tutela que podría reclamarse - ¿reparación de todos los perjuicios, solo de aquellos directamente asociados a infracciones o conductas cometidas tras la entrada en vigor de la norma? El enfoque elegido, además de ser más sencillo y beneficioso para los consumidores, resulta coherente con el carácter procesal del instrumento que se introduce con la directiva.

27. Debe señalarse, en todo caso, que los tiempos señalados por la directiva son amplios. Los Estados miembros disponen de 24 meses, desde su entrada en vigor, para trasponerla. Y resultará aplicable, en todo caso, una vez hayan transcurrido otros seis meses desde esa fecha máxima de trasposición (art. 24.1).

\section{Legitimación para el ejercicio de las acciones representativas}

\section{A) Exigencias diversas en función del carácter nacional o transfronterizo de la acción}

28. Uno de los elementos definitorios de la European way to collective redress es la existencia de un control público previo sobre la legitimación para ejercer las acciones en representación de los intereses colectivos de los consumidores. Ese era ya el núcleo de las directivas de 1998 y 2009 en relación con las acciones de carácter cesatorio e inhibitorio. Y, sin duda, se mantiene y se refuerza en la propuesta de 2018 y en el texto aprobado, que abre las puertas al ejercicio de acciones resarcitorias.

29. Según el diseño del legislador europeo las acciones colectivas han de interponerse necesariamente por entidades representativas habilitadas. Y esto significa, al menos, dos cosas:

30. - La primera, que las acciones colectivas no pueden interponerse válidamente por personas físicas a título individual y en representación de un conjunto de consumidores que se hallen en su misma situación. En otros términos, se excluye de raíz cualquier iniciativa singular y particular para impetrar tutela colectiva, a diferencia de lo que sucede en el sistema estadounidense de las class actions.

31. - La segunda, que no cualquier entidad que afirme su representatividad de los derechos e intereses de los consumidores está legitimada para promover un proceso colectivo, sino solo aquellas que hayan superado un filtro o control, establecido y gestionado por el poder público: dado su impacto más allá de lo individual, las acciones colectivas se consideran instrumentos de manejo delicado, que solo puede permitirse a entidades que resulten «fiables»-en terminología legal, «representativas»-. Y es el

${ }^{38}$ Al respecto cfr. E. De Luis García, "La tutela colectiva del medio ambiente”, en A. Montesinos García (dir.), La Tutela de los Derechos e Intereses Colectivos en la Justicia del Siglo XXI, Tirant lo Blanch, Valencia, 2020, pp. 345-358, en pp. 353-357. 
poder público el que se encarga no solo de establecer los requisitos de los que depende esa «fiabilidad» o «representatividad», sino también de verificar que se cumplen en una o varias entidades -al habilitarlas- y de controlar que se mantienen en el tiempo.

32. En este punto, de hecho, el iter legislativo ha provocado un cambio de enfoque de gran relevancia. El informe del Parlamento, haciendo suya en esto la propuesta inicial de la Comisión, apoyaba el establecimiento de una serie de requisitos comunes -y razonablemente exigentes- para que cualquier entidad pudiera habilitarse de cara al ejercicio de acciones representativas, con independencia del ámbito y del impacto geográfico que estas hubieran de tener. ${ }^{39}$ Tras la toma de posición del Consejo aparece -y se impone- una distinción clave, en función de si la acción representativa va a tener carácter puramente interno o transfronterizo. Según el art. 3.6, se ha de considerar como «acción de representación nacional» la que resulta interpuesta por una entidad habilitada en el Estado miembro en el que dicha entidad habilitada haya sido designada, aunque suponga reaccionar contra una infracción que haya podido tener impacto en otro u otros Estados miembros. Y estaremos ante una «acción de representación transfronteriza» (art. 3.7) cuando la interponga una entidad habilitada en un Estado miembro distinto del Estado miembro en el que dicha entidad habilitada haya sido acreditada.

33. Tratándose del ejercicio de acciones colectivas de ámbito nacional, el Considerando 26 de la directiva apunta que la Unión no debe establecer los requisitos de los que depende la habilitación de entidades para ejercerlas: estos deben existir, pero ha de ser cada legislador nacional quien los establezca, no la directiva. Se renuncia, pues, a armonizar en términos generales los criterios de legitimación para el ejercicio de acciones colectivas. Los criterios comunes, por ello, se reservan para las entidades que aspiren a estar habilitadas para el ejercicio de acciones colectivas transfronterizas (art. 4.3), esto es, para evitar que «cualquiera pueda venir de fuera a ejercer acciones colectivas en mi país». En efecto, lo único que exige la directiva en relación con la legitimación para el ejercicio de acciones representativas nacionales es (i) que las organizaciones de consumidores puedan acceder a la condición de entidades habilitadas (art. 4.3), (ii) que no se excluya la posibilidad de que se pueda otorgar la condición de entidades habilitadas a organismos públicos -como, en España, la Aecosan- (art. 4.7), (iii) que se pueda designar, a petición propia, a una entidad habilitada de forma específica para una acción de representación en particular (art. 4.6) y (iv) que resulte pública y accesible la lista de entidades habilitadas para el ejercicio de acciones representativas (art. 5.2). Se trata de exigencias que, como puede apreciarse, no afectan a los requisitos de los que depende la atribución de legitimación para el ejercicio de acciones nacionales.

34. Debe recordarse, en este sentido, que uno de los propósitos del legislador europeo, desde la primera regulación de las acciones de cesación, ha sido precisamente el de permitir que entidades legitimadas para el ejercicio de acciones colectivas en un Estado miembro puedan también interponerlas en cualquier otro Estado miembro, si se comprueba que la infracción a las normas protectoras de los consumidores tiene alcance transfronterizo. En el ámbito de las acciones de cesación, de hecho, se viene produciendo una suerte de «reconocimiento mutuo de habilitaciones nacionales»: cada Estado miembro suministraba periódicamente un listado a la Comisión Europea con las entidades legitimadas para el ejercicio de acciones de cesación; con todos los datos la Comisión publicaba, a su vez, un elenco de entidades habilitadas para el ejercicio, de modo que la inclusión en él obligaba a las autoridades judiciales o administrativas de los demás Estados miembros a presumir su capacidad jurídica para actuar, sin perjuicio de poder controlar si en el caso concreto la finalidad de la entidad habilitada justificaba el ejercicio de acciones (art. 4.1 de la Directiva 2009/22).

\footnotetext{
${ }^{39}$ En relación con esta primera versión cfr. J. LóPEZ SÁNCHEZ, "La Propuesta de directiva sobre acciones de representación para la protección de los intereses colectivos de los consumidores y el ámbito de representación de las entidades habilitadas para su ejercicio", cit., pp. 413-421; J. MARTín PASTOR, Las técnicas de reparación judicial colectiva en el proceso civil. De las incipientes acciones colectivas a la tradicional acumulación de acciones, Tirant lo Blanch, Valencia, 2019, pp. 131-133; T. Armenta Deu, "La legitimación en las acciones colectivas", en A. Montesinos García (dir.), La Tutela de los Derechos e Intereses Colectivos en la Justicia del Siglo XXI, cit., pp. 103-148, en pp. 135-138.
} 
35. La nueva directiva abunda en esta idea, pues lo relevante no es el ámbito de la infracción, sino la nacionalidad de la entidad que pretende el ejercicio de la acción representativa. Cuando una entidad nacional, habilitada conforme al Derecho nacional, ejerza una acción representativa ante un tribunal de ese país, nada impide que la tutela pueda tener alcance transfronterizo -con los límites, eso sí, que dispone la propia directiva ${ }^{40}$. Lo que genera más reparos es que una entidad de otro Estado miembro pretenda ejercer acciones de trascendencia colectiva ante los tribunales propios, sin que exista certeza acerca de los estándares mínimos que se le han exigido en su Estado de origen para actuar en ese tipo de procesos. El salto respecto del régimen de las acciones de cesación consiste, pues, en dejar de conformarse con un reconocimiento automático y ciego de entidades habilitadas con arreglo a los diversos derechos nacionales, con el único filtro del control en concreto de la existencia de un vínculo suficiente entre la entidad y el litigio. Esto, que puede ser suficiente para acciones de cesación, no lo es para las acciones resarcitorias, cuyo impacto práctico puede ser muy superior. Los Estados miembros solo están dispuestos a permitir que entidades extranjeras ejerzan acciones colectivas ante sus tribunales o autoridades administrativas si estas cumplen con unos estándares más exigentes, que eviten distorsiones y abusos.

\section{B) Los estándares europeos para la atribución de legitimación extraordinaria de cara al ejercicio de acciones colectivas}

36. Según el art. 4.3 solo podrán acreditarse como entidades representativas habilitadas para el ejercicio de acciones colectivas transfronterizas aquellas que cumplan con las siguientes condiciones:

37. a) Ha de tratarse de una persona jurídica debidamente constituida con arreglo a la legislación del Estado miembro de designación y que pueda demostrar que ha desempeñado una actividad pública real durante doce meses en el ámbito de la protección de los intereses de los consumidores: se quiere evitar así la creación de «vehículos ad hoc», aunque la propia directiva, al igual que para las acciones nacionales, también permite la acreditación de entidades para el ejercicio de una acción transfronteriza determinada (art. 4.6).

38. b) Con arreglo a sus estatutos, la entidad ha de ostentar un interés legítimo en proteger los intereses de los consumidores: de hecho, y también de forma equivalente a lo señalado para las entidades habilitadas para el ejercicio de acciones nacionales, se indica la conveniencia de promover la acreditación de organizaciones de consumidores (art. 4.2) y se contempla asimismo la posibilidad de acreditar a organismos públicos (art. 4.7).

39. c) Ha de tratarse de una entidad sin ánimo de lucro: la concurrencia de este requisito, con frecuencia, puede deducirse de la forma jurídica empleada para su incorporación y/o de sus estatutos o título constitutivo.

40. d) La entidad no puede hallarse en situación de insolvencia o en proceso de ser declarada insolvente. La directiva aspira, con ello, a que la entidad disfrute de una situación financiera sana y estable, como forma de combatir el riesgo de influencias indebidas por parte de terceros. El umbral elegido es mínimo y hasta cierto punto formal: no haber caído en situación de insolvencia. Exigencias superiores podrían haber sido difíciles de implementar en la práctica. Es sabido, en efecto, que la posición económica de las asociaciones de consumidores en muchos Estados miembros es delicada, en la medida en que descansa en las cuotas de los asociados. En el nuestro, de hecho, la fragilidad financiera de las asociaciones de consumidores es uno de los factores -desde luego, no el único-que explican el escaso uso del modelo de acciones colectivas vigente desde la entrada en vigor de la LEC.

\footnotetext{
${ }^{40}$ Cfr. infra, núm. 65: se trata, básicamente, de imponer una suerte de opt-in para que los efectos del proceso se proyecten sobre consumidores con residencia habitual en otro Estado miembro (art. 9.3).
} 
Consciente de esta dificultad, el legislador europeo parece decidido a obligar a los Estados miembros a adoptar medidas que garanticen que los costes procesales asociados al ejercicio de acciones de representación no se conviertan en obstáculos insalvables para que estas activen la legitimación que tienen conferida (arts. 20.1 y 20.2). La previsión, sin embargo, no va más allá de lo genérico, sin concretarse en un deber público de contribuir a su financiación: la financiación pública es una opción, pero se sugieren otras, como la reducción de tasas judiciales, la prestación de asistencia jurídica gratuita a las entidades o incluso la contribución de los propios consumidores afectados por la infracción al sostenimiento de los gastos procesales, a través de la aportación cantidades «modestas» (art. 20.4).

41. e) Ha de gozar de independencia, en el sentido de que no puede estar recibiendo influencias de personas distintas de los consumidores que tengan un interés económico en interponer una acción de representación determinada, especialmente si se trata de empresarios -que pueden ser competidores-. Esta ausencia de vínculos ha de analizarse con atención en caso de que la entidad reciba financiación de terceros. Además, la entidad ha de disponer de procedimientos internos para evitar tales influencias.

42. f) La entidad difunde públicamente por cualquier medio adecuado, especialmente a través de su sitio web, información sobre los criterios enumerados anteriormente y sobre las fuentes de financiación de su actividad en general.

43. Al igual que sucede con las entidades acreditadas para el ejercicio de acciones representativas de ámbito nacional, cada Estado miembro habrá de elaborar y mantener actualizada una lista con las que hayan sido designadas para el ejercicio de acciones transfronterizas (art. 5.1). Sobre la base de la información remitida por cada Estado miembro, la Comisión Europea elaborará y publicará una lista completa de entidades, que se actualizará anualmente y siempre que se comuniquen modificaciones. Se prevén, además, dos tipos de control adicional:

- Los Estados miembros tienen que evaluar al menos cada cinco años si las entidades habilitadas siguen cumpliendo los criterios exigidos en la directiva y deben privar de esa condición a aquellas que hayan dejado de cumplir alguno de ellos (art. 5.3).

- Otro Estado miembro y la propia Comisión Europea pueden también plantear dudas acerca del cumplimiento por una entidad habilitada de los criterios exigidos por la directiva-deben crearse puntos de contacto nacionales para hacerlo posible-. En tal caso, el Estado miembro que la haya acreditado deberá desarrollar la investigación pertinente y, si procede, deberá revocar la acreditación. La misma facultad se atribuye a quien resulte demandado en un caso concreto (art. 5.4).

\section{C) Controles al ejercicio de acciones por las entidades legitimadas}

44. Como puede advertirse, los requisitos son elevados y los controles -si se llevan a cabo con seriedad- son estrictos. Se trata con ello de concentrar el ejercicio de las acciones colectivas transfronterizas en unas pocas manos, evitando el riesgo de que una hipotética legitimación dispersa pueda dar lugar a pleitos abusivos o espurios.

45. Pero las precauciones no acaban aquí. Junto a las exigencias y requisitos generales, que han de cumplirse en todo caso para poder ejercer acciones colectivas transfronterizas, se plantea la creación de filtros y controles adicionales para cada caso concreto, encaminados igualmente a prevenir posibles instrumentalizaciones fraudulentas de la acción colectiva. Algunas de estas exigencias tienen carácter general, mientras que otras salvaguardas se reservan para las acciones resarcitorias -que son aquellas en relación con las cuales se advierte una mayor necesidad de intervención armonizadora por parte de la Unión-. 
46. En primer lugar, se ha incorporado a la directiva un precepto que, de forma general, permite que los tribunales o autoridades administrativas ante quienes se ejerza la acción representativa la sobresean lo antes posible si la consideran manifiestamente infundada (art. 7.7). Se trata, como puede apreciarse, de una herramienta en apariencia muy potente frente a un hipotético abuso de las acciones representativas, aunque deben tenerse en cuenta varios extremos:

(i) De entrada, debe notarse que la directiva no obliga a sobreseer las acciones infundadas, pero sí obliga a que las legislaciones procesales nacionales permitan que los tribunales -0 , allí donde el sistema sea ese, las autoridades administrativas- lo hagan si así lo consideran oportuno. Aunque parezca un sofisma, tiene implicaciones en dos sentidos: de un lado, evita automatismos, siempre delicados cuando se trata del ejercicio de acciones; pero, de otro, al incluir este precepto la directiva tiene el potencial de imponer un cambio normativo importante, al menos en ordenamientos procesales como el nuestro, ${ }^{41}$ para los que la inadmisión inicial de una demanda o su sobreseimiento solo son posibles en casos tasados y por razones procesales -solo muy excepcionalmente por motivos de fondo.

(ii) La directiva apenas ofrece indicaciones de índole procedimental, sino que efectúa una remisión a la legislación procesal nacional, con una sola guía: el sobreseimiento ha de producirse en la etapa procesal más temprana posible. La activación de oficio, en todo caso, ha de resultar posible, dada la formulación genérica del precepto y, sobre todo, si se tiene en cuenta su finalidad, que es coherente con el espíritu general de la directiva de evitar el empleo abusivo de las acciones colectivas.

(iii) En cuanto al núcleo del precepto, debe subrayarse que los criterios de los que depende que la acción se considere manifiestamente infundada no pueden ser solo formales (v.g., que la entidad no cumpla con los requisitos internos o europeos para el ejercicio de acciones colectivas), pues para eso no sería necesaria una norma como esta. Antes bien, lo que el precepto está contemplando es una ausencia de fundamento en cuanto al fondo de la pretensión colectiva ejercitada, pues a eso hace referencia el término «infundado». En la práctica, por tanto, las dificultades estarán en el terreno de los límites, teniendo claro que se ha impuesto un umbral elevado con el empleo del adverbio «manifiestamente». Debe señalarse, en relación con esto, que lo que determina la posibilidad de sobreseimiento temprano de la causa no es, al menos según el tenor literal del precepto, su carácter abusivo; ahora bien, es evidente que bajo el paraguas de lo «manifiestamente infundado» se puede incluir la pretensión ejercitada de manera abusiva.

47. En segundo término, y en consonancia con lo ya establecido para las acciones de cesación en las directivas de 1998 y 2009, se parte de la premisa de que la inclusión de la entidad demandante en la lista de entidades habilitadas solo acredita que cumple los requisitos necesarios para ejercer una acción colectiva transfronteriza, pero ha de verificarse, en el caso concreto, la vinculación entre el concreto proceso y la finalidad estatutaria de la entidad habilitada (art. 6.3): solo si hay conexión suficiente entre ambos extremos cabrá entender que tiene conferida la legitimación extraordinaria necesaria para promover la tutela representativa de los consumidores afectados por la infracción.

48. Pero los controles más severos afectan a la financiación para el ejercicio de la acción representativa cuando pretenda la obtención de tutela resarcitoria. El incremento de las modalidades de financiación de litigios por terceros (third party funding) también puede proyectarlas sobre los procesos

${ }^{41}$ Es cierto que el art. 11.2 LOPJ señala que "Los Juzgados y Tribunales rechazarán fundadamente las peticiones, incidentes y excepciones que se formulen con manifiesto abuso de derecho o entrañen fraude de ley o procesal". En la misma línea, el art. 247.2 LEC establece que "Los tribunales rechazarán fundadamente las peticiones e incidentes que se formulen con manifiesto abuso de derecho o entrañen fraude de ley o procesal". Estos preceptos, sin embargo, no parecen estar pensados para justificar una inadmisión a trámite de demandas infundadas o un sobreseimiento por ese motivo de procesos en curso (cfr. A. Muñoz Aranguren, La litigación abusiva, cit., passim). La regla, antes bien, es la del art. 403.1 LEC, en virtud del cual "Las demandas sólo se inadmitirán en los casos y por las causas expresamente previstas en esta Ley". 
colectivos - como sucede notoriamente en Estados Unidos o en Australia-. Lo que se pretende con la directiva es evitar que tras la financiación por un tercero se oculte un conflicto de interés que redunde en un carácter abusivo o fraudulento del proceso para el ejercicio de la acción representativa. A tal fin, el art. 10.1 establece el deber general de los Estados de velar por que, en los casos en que el litigio esté financiado por un tercero -y esto será posible en la medida en que lo permita la legislación nacional-, se eviten los conflictos de interés y que, si el tercero financiador tiene un interés económico en la interposición de la demanda o en el resultado del proceso, no se vea comprometido el objetivo de la acción de tutelar los intereses colectivos de los consumidores (art. 10.1). El conflicto de interés que se quiere excluir se puede plasmar, al menos, de dos maneras diversas -y no excluyentes-, descritas en el art. 10.2: en primer término, si las decisiones de la entidad habilitada que está ejercitando la acción se ven indebidamente influidas por un tercero, de modo que resulten perjudiciales para los intereses colectivos de los consumidores afectados (incluidas las decisiones en relación con transacciones); en segundo término, si la acción representativa se interpone frente a una entidad que sea competidora del tercero financiador o de la que dependa dicho financiador (en este caso, cabe presumir la existencia de una influencia indebida incompatible con la utilización de la acción representativa). Para evitar la materialización de estos riesgos se establecen dos previsiones complementarias, una de medios y otra de resultados.

(i) En cuanto a lo primero, el tribunal que conozca de la acción está facultado para verificar si efectivamente pudiera estar dándose un conflicto de interés, en caso de que surjan dudas justificadas al respecto (art. 10.3). A tal fin, la entidad demandante habrá de presentar al tribunal un resumen financiero, incluyendo las fuentes de financiación utilizadas para sostener la acción ${ }^{42}$. Aunque la redacción del precepto no es clara, parece lógico entender que la aportación de este resumen financiero es necesaria en todo caso, pues solo tras verificar que existe financiación de terceros pueden nacer en el tribunal las dudas justificadas que le faculten para verificar que no concurre una situación de conflicto de interés. Y, por supuesto, cabe entender igualmente que el tribunal estará facultado para apreciar la existencia del conflicto de interés en cualquier momento del proceso, esto es, en cuanto advierta que alguna decisión de la entidad demandante podría ser perjudicial para los intereses de los consumidores.

(ii) Por lo que se refiere a las consecuencias en caso de que se advierta un conflicto de interés, el art. 10.4 obliga a los Estados a dotar a los tribunales de facultades para tomar las medidas adecuadas, como exigir a la entidad demandante que rechace o cambie la financiación que genera el conflicto; en último término, el tribunal puede denegar la legitimación a la entidad demandante para el ejercicio de la acción en cuestión -denegación que, en todo caso, no puede afectar a los derechos de los consumidores concernidos.

La directiva, como se advierte desde un principio en el art. 10.1, no aspira a regular de forma plena el fenómeno del third party funding en el ámbito de las acciones colectivas. No obstante, cabe apreciar que impone una serie de límites a las legislaciones nacionales y, sobre todo, que ha dispuesto las herramientas adecuadas para forzar su cumplimiento. Téngase en cuenta, además, que se aplican a todas las acciones que encajen en la noción de acción representativa resarcitoria según la propia directiva, y no solo a las transfronterizas: el impacto, por tanto, será general. Se trata, sin duda, de una faceta en la que el impulso armonizador es más visible, precisamente porque abunda en esa policy recurrente de la directiva, consistente en evitar los peligros asociados a las class actions estadounidenses.

49. Los requisitos establecidos para que una entidad pueda estar legitimada en abstracto para el ejercicio de acciones colectivas transfronterizas (art. 4.3) y los diversos controles a los que se somete en

${ }^{42}$ La previsión normativa aprobada es bastante escueta al respecto. La Comisión y el Parlamento (art. 7.1 de la Propuesta) proponían, con algo más de detalle, la aportación de un resumen financiero de todas las fuentes de los fondos utilizados para su actividad en general y los fondos que utiliza para respaldar la acción, así como la demostración de que dispone de recursos financieros suficientes para representar los intereses de los consumidores afectados y para hacer frente a cualquier coste adverso en caso de que la acción no prospere. 
concreto el ejercicio de esa legitimación le sirven a la directiva para marcar el estándar europeo en relación con la mejor manera de asegurar una atribución adecuada y un ejercicio legítimo de la legitimación extraordinaria para la tutela colectiva de los derechos de los consumidores. Y no es infrecuente que el establecimiento de estándares europeos sirva de acicate o estímulo para adaptar a ellos las reglas nacionales: la necesidad de adaptar la normativa interna, impuesta por la directiva aunque sea en un ámbito concreto, puede ser una oportunidad para revisar si el régimen legal nacional es adecuado o si puede mejorarse tomando como ejemplo aquella. ${ }^{43} \mathrm{Al}$ fin y al cabo, resulta difícilmente explicable a justiciables y operadores jurídicos que se observen prevenciones más altas en ciertos sectores concretos, que sin embargo no se exigen para situaciones asimilables. La directiva, de hecho, es plenamente consciente de este fenómeno -«Europa como oportunidad»- y lo modula a través de dos fórmulas complementarias.

(i) De un lado, haciendo visible el deber de los Estados miembros de atenerse a las exigencias del principio de efectividad. En este sentido, el art. 4.4 establece que los requisitos que establezcan los legisladores nacionales para atribuir legitimación de cara al ejercicio de acciones representativas nacionales han de ser congruentes con los objetivos de la propia directiva de lograr un funcionamiento eficaz y eficiente de este tipo de acciones.

(ii) De otro lado, sugiere en el art. 4.5 que los Estados miembros apliquen para acreditar como entidades habilitadas para el ejercicio de acciones colectivas internas los mismos requisitos que la propia directiva impone a las transfronterizas.

\section{D) Título de legitimación de las entidades habilitadas}

50. Al margen de lo anterior, cabe preguntarse por el título de legitimación de las entidades habilitadas para el ejercicio de acciones colectivas. En este punto, la directiva huye de cualquier tipo de dogmatismo, por lo que cabe remitirse a las construcciones formuladas en doctrina, en jurisprudencia y en alguna legislación nacional acerca de la legitimación extraordinaria para el ejercicio de acciones colectivas. ${ }^{44}$ Como ya se apuntó antes, la directiva utiliza la expresión «acción de representación» de manera inevitablemente impropia, para tratar de transmitir el núcleo del fenómeno, consistente en desplazar el ejercicio de la acción a un sujeto que no es titular de los derechos o intereses lesionados por la infracción, pero que se considera adecuadamente representativo lato sensu de aquellos. En este sentido, el informe del Parlamento proponía definir la acción de representación como «toda acción para la protección de los intereses colectivos de los consumidores en la que los consumidores afectados no son parte» (art. 3.4). Nada impide, sin embargo, que uno o varios consumidores individuales se sumen a la acción -si así lo contempla la normativa procesal nacional-, razón por la cual el texto definitivo, de forma más aséptica aún, la define en el art. 3.5 como «toda acción para la protección de los intereses colectivos de los consumidores interpuesta por una entidad habilitada en calidad de demandante y destinada a obtener una medida de cesación o de reparación, o ambas».

51. Sea como fuere, lo relevante del sistema es que la legitimación principal no está en manos de los consumidores afectados a título individual, ni tampoco agrupados, sino que se concentra en las entidades habilitadas. Esta decisión tampoco prejuzga una hipotética apuesta del legislador europeo por un modelo opt-in u opt-out. En esto la directiva aspira a ser lo más neutra posible, al menos en lo relativo al ejercicio de acciones resarcitorias: la expresión «acción de representación» no prejuzga ni asumir que las entidades habilitadas representan ex lege a los consumidores (algo similar a un modelo de opt-out forzoso), ni tampoco que las entidades habilitadas deban contar con un mandato o autorización previa de los consumidores afectados para ejercer una acción que pueda acabar redundando en su beneficio

\footnotetext{
${ }^{43}$ Sobre esto, cfr. F. Gascón Inchausti, Derecho europeo y legislación procesal civil nacional: entre autonomía y armonización, Marcial Pons, Madrid-Barcelona-Buenos Aires-Sao Paulo, 2018, pp. 131 y ss.

${ }^{44}$ Un análisis reciente y omnicomprensivo puede verse en S. CoRominas BACH, Procesos colectivos y legitimación. Un necesario salto hacia el futuro, Marcial Pons, Madrid-Barcelona-Buenos Aires-Sao Paulo, 2018.
} 
(un modelo opt-in). La heterogeneidad de los sistemas procesales nacionales en este punto y la falta de voluntad de las instituciones europeas de alterar los equilibrios alcanzados al respecto en cada Estado miembro han determinado un alto grado de neutralidad normativa sobre esta cuestión, bien distinto a la clara apuesta por el modelo opt-in que se formulaba por la Recomendación de la Comisión de 2013 para las acciones resarcitorias.

\section{Tutelas disponibles: la accionabilidad colectiva}

52. El segundo gran objetivo de la directiva $-y$ posiblemente la explicación de por qué se ha tardado tanto en llegar a ella y de por qué ha resultando tan compleja su aprobación- es abrir la puerta al ejercicio de acciones colectivas que tengan un contenido resarcitorio: ha de recordarse que la existencia de acciones de contenido cesatorio e inhibitorio era ya un fenómeno habitual, tras la incorporación en los Estados miembros de la Directiva de 1998. La nueva directiva, por tanto, se adentra en el terreno de la accionabilidad y establece los tipos de tutela que pueden solicitar eficazmente las entidades legitimadas para la protección de los consumidores.

53. Para el legislador europeo existe una línea divisoria muy definida entre la tutela cesatoria/ inhibitoria y la tutela reparadora/resarcitoria: se trata de un binomio que figura en los primeros documentos, que se hace claramente visible en la Recomendación de la Comisión de 2013 y que se consolida definitivamente con la nueva directiva. Para evitar dudas o interferencias doctrinales, el legislador trata de definir con precisión cuáles son los posibles contenidos de cada una de estas modalidades de tutela, a las que denomina respectivamente «medidas de cesación» $\mathrm{y}$ «medidas de reparación»-y nuevamente la terminología puede verse como arbitraria, pues en ocasiones la reparación puede conseguirse a través de la mera cesación.

\section{A) Pretensiones de cesación}

54. La regulación de las «medidas de cesación» se hereda de las directivas de 1998 y 2009. Su contenido es claro: que se dirija al empresario o profesional una orden conminándolo a cesar en una práctica que se considere constitutiva de una infracción o prohibiéndole desarrollar o reanudar una práctica infractora. Es indiferente, por tanto, que la conducta infractora haya cesado ya cuando se interpone la demanda, si existe el riesgo de que se reanude. ${ }^{45}$

55. Tanto la directiva de 2009 -siguiendo lo previsto en la de 1998- como la nueva directiva, además, distinguen en este punto entre medidas provisionales y medidas definitivas (art. 8.1). Las medidas definitivas, en nuestra terminología, encajan sin más en la categoría de las condenas de no hacer y se adoptan, por tanto, tras un proceso declarativo, que se tramitará con arreglo a las normas procedimentales establecidas en cada Estado ${ }^{46}$. En cuanto a las provisionales, todo depende del régimen procesal de cada Estado miembro. En nuestro ordenamiento los mandatos provisionales de cesación o prohibición han de articularse a través de la institución de las medidas cautelares, caracterizadas por una relación de instrumentalidad estricta, que obliga a incoar un proceso en cuanto al fondo en un plazo de veinte días -en caso de que se soliciten con antelación- (art. 730.2 LEC). En otros ordenamientos la configuración de la tutela provisional y cautelar es más flexible, pues la eficacia de la orden provisional no está supeditada a la pendencia o a la incoación de un proceso en cuanto al fondo -así será, v.g., si lo solicita la parte destinataria

\footnotetext{
${ }^{45}$ Lo aclara, de hecho, el art. 2, al definir el ámbito de aplicación de la propia directiva.

${ }^{46}$ En España, como se recordará, la reforma de la LEC operada por la Ley 39/2002, de 29 de octubre, destinada a implementar la directiva de 1998, optó por la vía del juicio verbal, posiblemente para transmitir la imagen de mayor celeridad y eficacia que parecen ir asociadas a este cauce procedimental.
} 
de la orden de cesación ${ }^{47}$. A mi juicio una concepción más flexible de la instrumentalidad de las medidas cautelares -al estilo alemán- constituiría una clara mejora de nuestro sistema de tutela judicial, al menos cuando se trata de medidas cautelares de contenido anticipatorio. Ahora bien, ni las directivas de 1998 y 2009 obligaban a efectuar semejante cambio para implementar el deber de disponer de «medidas provisionales de cesación» ni, en consecuencia, se desprende dicho deber tampoco de la nueva directiva.

56. En línea igualmente con lo previsto en la directiva de 2009, también puede formar parte de la tutela cesatoria la obligación de publicar total o parcialmente la resolución sobre la medida, en la forma que se estime conveniente, o que se publique una declaración rectificativa [art. 8.2 b)]: en la mayoría de los casos, este contenido adicional se convertirá en una obligación de hacer frente a los costes de la publicación, si esta no se lleva a cabo espontáneamente.

57. Y es igualmente heredera de la regulación aún vigente la posibilidad de supeditar el ejercicio de la acción de cesación definitiva a una «consulta», si así lo deciden los legisladores nacionales (art. 8.4). En tal caso, será preceptivo formular una solicitud de consulta al empresario; si este no cesa en la infracción en un plazo de dos semanas, la entidad habilitada podrá interponer una acción de representación para solicitar dicha medida de cesación sin más trámite. Se trata de una regla pensada en beneficio de ambas partes, pues puede evitarles los costes del proceso.

58. A partir de aquí, la directiva aporta una serie de previsiones adicionales, que vienen a completar y mejorar el régimen previo de las acciones de cesación, imponiendo deberes y límites a los legisladores nacionales a la hora de efectuar su incorporación:

(i) En primer lugar, resulta novedosa la previsión de que, como contenido de la orden de cesación, se incluya «una medida destinada a establecer que la práctica constituye una infracción» [art. 8.2 a)]. Aunque la expresión sea tosca, se entiende que hace referencia a la declaración de ilicitud de la práctica: bajo la etiqueta de las «medidas de cesación», por tanto, se incluyen también pretensiones meramente declarativas, que deben poder pedirse y concederse a título principal, para que puedan servir en su caso de fundamento a pretensiones ulteriores. Según el texto aprobado, esta pretensión podrá supeditarse a lo establecido en la legislación procesal nacional. A mi juicio, esto en la práctica puede determinar la inviabilidad de formular este tipo de pretensiones declarativas a título provisional o cautelar, al menos en sistemas como el nuestro, en que las medidas cautelares son rigurosamente instrumentales. Tiene lógica, en todo caso, presumir que una declaración de ilicitud debe integrarse en una resolución sobre el fondo del litigio, susceptible de producir efectos vinculantes -cabe pensar, sobre todo, en los de cosa juzgada- respecto de procesos o peticiones ulteriores.

(ii) En segundo término, se establece que la estimación de la acción de cesación no se pueda supeditar a la prueba de pérdidas o perjuicios reales por parte de los consumidores individuales afectados por la infracción ni de la intención o negligencia por parte del empresario (art. 8.3). Se resalta con ello que a través de la acción de cesación, en sus diversas modalidades, se lleva a cabo un control abstracto sobre la licitud o ilicitud de una práctica, al margen de sus repercusiones reales, que desemboca en la orden de cesación. Visto desde el ángulo inverso, puede decirse también que la orden de cesación solo resulta legítima previa afirmación de que la conducta es infractora.

(iii) Finalmente, se prohíbe que las legislaciones nacionales de desarrollo de la directiva exijan a los consumidores afectados por una acción de representación dirigida a obtener una medida de cesación que participen en dicha acción de representación (art. 8.3). Puede decirse, en otros términos, que se excluye la admisibilidad de un modelo opt-in respecto de este

\footnotetext{
${ }^{47}$ Así ocurre, v.g., con la Leistungsverfügung alemana, la ordonnance de référé francesa, el kort geding holandés o las medidas anticipatorias del ordenamiento italiano, entre otros.
} 
tipo de pretensiones. Se trata de algo lógico, pues el control que se efectúa es general o abstracto, atendiendo no al interés lesionado de los consumidores a título individual, sino de forma colectiva en el sentido más literal de la expresión: se busca «limpiar el mercado o el tráfico jurídico» de conductas y prácticas ilícitas, al margen de la situación individual de los consumidores. Por ello, no tiene sentido exigir ni la participación de estos, ni el otorgamiento por ellos de algún tipo de poder de representación o de autorización.

59. Las pretensiones de cesación -y, en su caso, de prohibición- tienen naturaleza condenatoria, de modo que en caso de incumplimiento se abren las puertas a la ejecución forzosa. En línea con el régimen precedente, la directiva seguirá obligando a los Estados miembros a articular esta ejecución sobre la base de la imposición de sanciones en caso de incumplimiento o de negativa a cumplir la medida acordada por el tribunal. Las sanciones podrán adoptar la forma de multas coercitivas y habrán de ser «eficaces, proporcionadas y disuasorias» (art. 19).

\section{B) Pretensiones de reparación}

\section{a) Contenido de la tutela reparatoria}

60. Desde las primeras iniciativas, y sobre la base de la Recomendación de 2013, las instituciones europeas advierten que la reparación a los consumidores perjudicados por una práctica ilícita puede lograrse de formas diversas, en función de las circunstancias de cada caso. Por ello, se ha optado por establecer una fórmula muy genérica, la de «medidas de reparación» o «medidas correctoras para los consumidores afectados», seguida de una lista ejemplificativa de posibles plasmaciones concretas de esa corrección: una indemnización, una reparación o arreglo, una sustitución, una reducción del precio ${ }^{48}$, la resolución del contrato o el reembolso del precio pagado, según proceda y conforme a la legislación de la Unión o nacional (art. 9.1).

61. Bajo la etiqueta de «medidas de reparación», por tanto, el legislador europeo quiere dar cabida a todas aquellas pretensiones que desemboquen en la imposición al comerciante del deber de llevar a cabo una o varias conductas en favor de los consumidores afectados -acciones de condena-; debe advertirse, asimismo, que también encajan en esta noción pretensiones constitutivas, como sucede con la resolución contractual. Los límites, por tanto, derivarán del contenido concreto de los derechos lesionados y de los remedios que la legislación europea y/o nacional asocien a su infracción.

62. El informe del Parlamento (art. 6, aptdo. 4 ter), siguiendo en esto la propuesta inicial de la Comisión y la Recomendación de 2013, pretendió añadir un límite al contenido de la tutela reparatoria: la prohibición de los llamados daños punitivos, esto es, de las indemnizaciones que conceden a la parte demandante una cantidad superior al valor del daño sufrido. ${ }^{49} \mathrm{El}$ texto aprobado no alude expresamente a ello en su parte dispositiva, aunque el considerando 42 es explícito: "This Directive should not enable punitive damages being imposed on the infringing trader, in accordance with national law". En consecuencia, la exclusión de los daños punitivos se puede deducir, para cada Estado miembro, de la remisión a la legislación nacional: allí donde los punitive damages estén prohibidos -como ocurre en España y en los Estados miembros de tradición jurídica continental-, tampoco podrán concederse en el marco de una acción colectiva de reparación. Esta técnica legislativa de «remisión por omisión», sin embargo,

\footnotetext{
${ }^{48}$ Como señala LóPez SÁNCHez, "la reducción del precio sólo tiene sentido en relación jurídica continuada en el tiempo que exija la realización de nuevas prestaciones por parte del "comerciante"” (J. LópEz SÁNCHEZ, "La Propuesta de directiva sobre acciones de representación para la protección de los intereses colectivos de los consumidores y el ámbito de representación de las entidades habilitadas para su ejercicio", cit., p. 415).

${ }^{49}$ Cfr. F. Parisi, M.S. Cenini, "Punitive damages and class actions", en J.G. Backhaus, A. Cassone, G.B. Ramello (eds.), The Law and Economics of Class Actions in Europe. Lessons from America, Edward Elgar, Cheltenham, 2012, pp. 131-146.
} 
comporta un riesgo claro: que se formulen acciones colectivas transfronterizas en algún Estado miembro que sí admita los daños punitivos o una figura equivalente (como los exemplary damages irlandeses), abriendo con ello la puerta al forum shopping ${ }^{50} \mathrm{y}$ a un riesgo de acciones colectivas abusivas.

63. Más allá del contenido en sí de las pretensiones reparatorias, la directiva también aborda otras cuestiones, relativas a los requisitos para su ejercicio válido y a su eficacia.

\section{b) ¿Opt-in u opt-out?}

64. La primera pregunta que se plantea cuando se diseña un sistema de tutela colectiva que permita condenar a la realización de prestaciones a favor de sujetos no litigantes es la relativa a si se considera necesaria o no la adhesión a la acción de los consumidores afectados para que el proceso pueda desarrollarse o, al menos, para que el pronunciamiento que se dicte pueda proyectarse respecto de aquellos: se trata, en otros términos, de determinar si se elige un modelo opt-in o un modelo optout. Si la Recomendación de 2013 era claramente partidaria de lo primero, la directiva opta por una mayor neutralidad. En términos generales, los Estados miembros podrán decidir si establecen normas sobre la manera y la fase en que los consumidores individuales afectados por la acción pueden expresar explícita o tácitamente su voluntad de ser representados o no por la entidad habilitada en el marco del proceso colectivo para obtener medidas de reparación y quedar vinculados por su resultado (art. 9.2). En función del tipo de norma que establezcan o que mantengan al trasponer la directiva, los Estados miembros se estarán decantando por un modelo de opt-in-si exigen una expresión de la voluntad de ser representado- o por un mecanismo de opt-out-si lo que se regula es la manera de no verse afectados ni por la acción ni por el resultado del proceso. Las ventajas e inconvenientes de cada mecanismo han sido sobradamente analizadas doctrinalmente ${ }^{51} \mathrm{y}$, por tanto, la opción por una u otra es cuestión de política legislativa: lo relevante es que, en términos generales, serán cuestión de política legislativa nacional, no europea. Ahora bien, es importante advertir sobre un extremo: la directiva quiere que los Estados regulen este asunto, es decir, que establezcan cuándo y cómo un consumidor individual ha de adherirse (opt-in) o cuándo ha de desvincularse (opt-out). No será admisible, en consecuencia, un sistema que se funde en una suerte de representación forzosa, en la que no resulte posible a un consumidor individual desvincularse: esto último, que es la regla para las acciones de cesación, no es aceptable cuando está en juego la reparación de los consumidores individuales ${ }^{52}$; en este contexto, pues, las cosas han de estar claras. Esta exigencia de definición tiene una derivada importante: en caso de acumulación de pretensiones cesatorias y resarcitorias en una misma demanda colectiva interpuesta por una entidad habilitada puede ser necesario conjugar las diversas reglas vigentes para unas y otras en cada Estado miembro.

65. Dentro de este contexto de libertad a la hora de configurar el ámbito subjetivo de las acciones representativas encaminadas a la obtención de medidas de reparación, sin embargo, el legislador europeo aspira a introducir algunas imposiciones a los legisladores nacionales.

${ }^{50}$ Cfr. C. PonciBò, "Forum shopping and consumer collective redress in action: the Costa Concordia case", en E. LeIN, D. Fairgrieve, M. Otero Crespo, V. Smith (eds.), Collective redress in Europe: why and how?, British Institute of International and Comparative Law, 2015, pp. 251-272.

${ }^{51}$ Cfr. T. Eisenberg, G. Miller, "The Role of Opt-Outs and Objectors in Class Action Litigation: Theoretical and Empirical Issues”, 57 Vand. L. Rev. (2004), pp. 1529 y ss.: según ese estudio, en promedio menos del $0.2 \%$ de los consumidores se excluyen de los procesos en Estados Unidos. Cfr. también R. Mulheron, "The case for an opt-out class action for European Member States: A legal and empirical analysis”, 15 Colum. J.Eur.L. (2008-2009), pp. 409 y ss.; A.L. SiBony, “A behavioural perspective on collective redress", en E. Lein, D. Fairgrieve, M. Otero Crespo, V. Smith (eds.), Collective redress in Europe: why and how?, British Institute of International and Comparative Law, 2015, pp. 47-57: A. Planchadell Gargallo, "Acciones colectivas y acceso a la justicia", en A. Montesinos García (dir.), La Tutela de los Derechos e Intereses Colectivos en la Justicia del Siglo XXI, cit., pp. 175-205, en pp. 195-201.

${ }_{52}$ Que es lo que sucedería actualmente en España, salvo que se acepte que la intervención de los consumidores individuales prevista en el art. 13 LEC puede tener como objetivo la desvinculación de la acción colectiva. 
(i) En primer término, se quiere que exista una regla común para situaciones transfronterizas: cuando estén en juego los derechos de consumidores individuales que no residan habitualmente en el Estado miembro en que se está ejercitando la acción, será necesario en todo caso que estos expresen explícitamente su voluntad de ser representados a fin de quedar vinculados por su resultado (art. 9.3). Se impone, pues, un modelo opt-in para los consumidores domiciliados en el extranjero, posiblemente para evitar problemas de coordinación entre modelos dispares, que podrían causar problemas a la hora de reconocer la eficacia de resoluciones extranjeras y, en su caso, de ejecutarlas.

(ii) Además, se añade una imposición adicional a los sistemas nacionales que opten por un modelo opt-in: si un consumidor ha expresado de manera explícita o tácita su voluntad de ser representado en una acción de representación, entonces no podrá ya ser representado en otra acción de representación, ni tampoco podrá interponer una acción individual contra el mismo empresario y que tenga el mismo objeto y causa (art. 9.4). La referencia a la expresión tácita de la voluntad permite albergar dudas razonables a favor de la aplicabilidad de esta regla también en los modelos que se hayan decantado por el opt-out. ${ }^{53}$

(iii) En tercer lugar, los Estados miembros deben asegurar que los consumidores no son compensados más de una vez por el mismo empresario respecto del mismo hecho dañoso (art. 9.4 i.f.).

(iv) Finalmente, en aquellos sistemas en que no se exija una adhesión explícita o tácita de los consumidores individuales -es decir, allí donde rija un modelo opt-out-, es posible que no puedan determinarse los consumidores individuales que pueden beneficiarse de las medidas correctoras establecidas por el tribunal (o autoridad administrativa): en tal caso, se deberá describir al menos el grupo de consumidores que pueden beneficiarse de aquellas (art. 9.5), cabe suponer que identificando las concretas circunstancias de las que se derive la condición de perjudicado y legitimado para obtener la reparación. ${ }^{54}$

En relación con esto último, se señala que la entidad habilitada, al interponer su demanda, ha de suministrar al tribunal (o autoridad administrativa) información suficiente en relación con los consumidores afectados por la acción (art. 7.2). El objetivo de esta exigencia no es único: de un lado, sirve posiblemente para acreditar la relación entre la entidad que pretende ejercer la acción y la concreta infracción frente a la que actúa, dado que sin una conexión suficiente la demanda puede considerarse inadmisible; pero, en lo que ahora interesa, sirve igualmente para sentar la carga de determinar con la mayor precisión posible quiénes son los afectados y, en consecuencia, quiénes y cuántos -al menos aproximadamente- son los potenciales beneficiarios de la tutela que se solicita.

\section{c) Eficacia de la tutela reparatoria}

66. En estrecha relación con lo anterior, debe advertirse cómo el legislador europeo también se ha preocupado de garantizar unos estándares mínimos de eficacia a las acciones colectivas resarcitorias, que se proyectan sobre planos diversos.

67. Desde un punto de vista procedimental, los Estados miembros han de asegurar que la medida de reparación permita a los consumidores reclamar -y obtener- la recuperación por los daños «sin necesidad de interponer otra acción» (art. 9.6). Esta previsión, interpretada en sentido estricto, comporta una suerte de deber de «desjudicialización» del cumplimiento y de la ejecución de la sentencia, en caso de que sea condenatoria ${ }^{55}$ : en otros términos, lo que parece querer el legislador europeo es que los con-

\footnotetext{
${ }^{53}$ Sobre esto, cfr. infra, núm. 88.

${ }^{54}$ En esto pues, la regulación de la directiva se asemeja al artículo 221.1.1 $1^{\mathrm{a}}$ de nuestra LEC.

${ }^{55}$ No sería operativa, en cambio, si la sentencia fuese constitutiva -en el caso de que la reparación del daño se hiciese efectiva, v.g., a través de la resolución del contrato-; en estos supuestos, la firmeza de la sentencia provocaría los efectos pretendidos, sin más. Podría ser precisa, no obstante, una ejecución impropia, pero sería secundaria o instrumental.
} 
sumidores no tengan que acudir a un procedimiento judicial -o administrativo- para que se les reconozca el derecho a beneficiarse del pronunciamiento estimatorio y acceder a la prestación que les deba el empresario. Desde una perspectiva interna, esta regla comportaría la necesidad de superar el modelo del art. 519 LEC, que obliga a los consumidores a pasar por un incidente previo para acceder a la ejecución de la sentencia. ${ }^{56}$ Obviamente, no puede evitarse que, en caso de denegación o discrepancia, la cuestión deba volver a sede judicial. Pero el sistema debe prever mecanismos que permitan el cumplimiento de la sentencia sin más y que, cuando los beneficiarios no estén identificados en ella, puedan aun así acceder a la reparación prevista sin tener que obtener refrendo judicial previo.

68. En relación con lo anterior, la directiva asume la posibilidad de que, cuando la reparación a los consumidores consista en el pago de una indemnización, se fije en la resolución una suma global, cuyo pago por el empresario condenado dé lugar a un fondo, que se encargue de gestionar posteriormente los abonos a los beneficiarios. ${ }^{57}$ Quedaría en manos de cada Estado miembro determinar quién y cómo habría de organizar y gestionar dichos fondos -tal vez la entidad legitimada para ejercer la acción, o un tercero-fiduciario-, así como determinar el destino de eventuales remanentes ${ }^{58}$.

69. Para que esta voluntad legal de máxima eficacia sea realidad, es preciso que los consumidores beneficiarios de la acción colectiva conozcan su existencia y, en su caso, que estén también informados de las medidas de reparación acordadas por un tribunal (o autoridad administrativa). La directiva centra parte de sus esfuerzos justamente en asegurar unos niveles adecuados de información a los consumidores acerca de la existencia del proceso incoado por la entidad habilitada y acerca de su desenlace, de modo que puedan ejercer sus derechos en cada contexto (art. 13.2). Son varios los canales de información previstos:

- De un lado, las propias entidades habilitadas, que han de informar-preferiblemente a través de sus webs- acerca de las acciones representativas que se plantean ejercer, del estado en que se encuentren y de su resultado (art. 13.1). En caso de que su pretensión sea estimada y hayan debido incurrir en costes adicionales de información, el empresario vencido habrá de reembolsárselos (art. 13.5). ${ }^{59}$

- De otro, los comerciantes demandados, en caso de que se les hayan impuesto medidas reparatorias en sentencia o de que las hayan aceptado en una transacción, que a petición del tribunal habrán de ponerlas en conocimiento de los consumidores beneficiarios: la información puede incluso tener que realizarse de forma individualizada, con los costes adicionales que esto puede provocar (art. 13.3).$^{60}$

70. Finalmente, la directiva exige que existan normas sobre los plazos para que los consumidores individuales se beneficien de las medidas de reparación (art. 9.7). Aunque no se diga expresamente, parece deseo del legislador que existan normas específicas, esto es, que la cuestión no deba regirse de forma genérica por los plazos ordinarios de caducidad o prescripción de acciones, como forma de promover un plus de seguridad jurídica.

\footnotetext{
${ }^{56}$ Sobre este mecanismo, de forma monográfica, cfr. R. LACUEVA BerTolacCi, Acción ejecutiva de consumidores y usuarios: el art. 519 LECiv, Aranzadi, Pamplona, 2006.

${ }^{57}$ En este sentido, el art. 9.7 señala lo siguiente: «Los Estados miembros podrán establecer normas sobre el destino de los fondos de reparación pendientes que no se hayan recuperado en los plazos establecidos».

${ }^{58}$ En relación con esto, el informe del Parlamento proponía establecer dos límites en cuanto al destino de ese hipotético remanente: no se puede devolver al comerciante, pero tampoco puede quedárselo la entidad habilitada que hubiera interpuesto la acción. Nada se dice al respecto en el texto finalmente aprobado, aunque la propuesta resulta más que razonable.

${ }^{59}$ Se trata de una regla importante, pues los costes de notificación pueden ser muy elevados y, por ende, disuasorios del ejercicio de acciones colectivos. En nuestro país, así lo ha puesto de manifiesto M.J. SANDE MAYo, Las acciones colectivas en defensa de los consumidores, Aranzadi, Cizur Menor, 2018, pp. 181-182.

${ }^{60}$ De forma inversa, también se puede ordenar a la entidad demandante que notifique a los consumidores afectados la inadmisión o la desestimación de la acción representativa (art. 13.4).
} 


\section{C) Relaciones entre cesación y reparación}

71. Aunque las acciones de cesación y las acciones de reparación son distintas, en la medida en que distintas son también las tutelas que prestan, a nadie escapa que pueden ser complementarias y, por tanto, que no tienen por qué presentarse separadas en la realidad. De un mismo hecho dañoso pueden derivarse acciones de trascendencia colectiva con contenidos diversos, que, a su vez, pueden ser objeto -o no- de un mismo proceso. Cuando resulte preciso, irá en interés de los consumidores que en un solo proceso puedan acumularse pretensiones de ambos tipos y el legislador europeo quiere promover que la normativa procesal interna no suponga un impedimento para ello. A tal fin, se ha dispuesto una regla bien sencilla: los Estados miembros han de poder permitir que las medidas de cesación y las de reparación se soliciten en una sola demanda y que se acuerden en una misma resolución (art. 7.5) ${ }^{61}$ Debe evitarse, por tanto, que previsiones procedimentales internas -como podrían ser, v.g., reglas diversas sobre competencia o adecuación procedimental- obstaculicen la consecución de estos dos objetivos.

72. De forma singular, se añade que las entidades habilitadas han de poder interponer acciones de representación para obtener medidas de reparación sin la condición de que un órgano jurisdiccional o una autoridad administrativa haya establecido previamente y mediante un procedimiento independiente que el daño sufrido por los consumidores deriva de una infracción (art. 9.8). La directiva pretende aclarar así dos extremos, bastante sensatos: de un lado, que el ejercicio de acciones de condena presupone la declaración de antijuridicidad de la conducta del demandado, aunque dicha declaración no se solicite a título principal y sin necesidad, menos aún, de que haya sido establecida con carácter previo; y, de otro, que el encuadramiento de las pretensiones declarativas de la existencia de una infracción en la categoría de las acciones de cesación ${ }^{62}$ no debe significar la imposibilidad de ejercerlas a título principal acumuladas a una pretensión de reparación.

\section{Herramientas procesales para reforzar la eficacia de las acciones representativas}

73. Las piezas esenciales sobre las que descansa el sistema que se introduce con la directiva son, sin duda, la limitación de la legitimación a una serie de entidades sujetas a niveles altos de supervisión pública y la determinación del contenido mínimo de la tutela judicial a la que se puede aspirar en estos procesos colectivos. A ellas se suman otras piezas de carácter netamente procesal, encaminadas a reforzar la eficacia de las acciones representativas, aunque de forma un tanto desigual.

\section{A) Acceso a pruebas}

74. Un elemento que caracteriza en gran medida los litigios en materia de consumo, incluidos los colectivos, es que una parte importante de las pruebas se halla en poder del empresario demandado o de terceros. El acceso a las fuentes de prueba relevantes es una premisa sin la que las entidades habilitadas no podrán ejercer las facultades que se les reconocen: se arriesgan a tener que asumir los costes de un proceso abocado al fracaso si no existe suficiente apoyo probatorio.

75. La directiva, sin embargo, no aspira a mostrarse en este punto especialmente incisiva, a pesar de que contaba para ello con el modelo diseñado en 2014 para las acciones de daños derivados de infracciones a las normas sobre defensa de competencia ${ }^{63}$. Ahora, sin embargo, el legislador europeo

\footnotetext{
${ }^{61}$ En nuestro ordenamiento, de hecho, se admite abiertamente que pretensiones de cesación se acompañen en un mismo proceso de pretensiones de reparación colectiva: cfr. en este sentido el artículo 53 TRDCU (tras la reforma operada por la Ley 3/2014, de 27 de marzo) o el artículo 12.2 II LCGC.

${ }^{62}$ Cfr. supra, núm. 58.

${ }^{63}$ Cfr. F. GASCÓN InChausti, «El acceso a las fuentes de prueba en los procesos civiles por daños derivados de infracciones de las normas sobre defensa de la competencia», La Ley Mercantil, 2017, núm. 38 (julio), pp. 1-18.
} 
parece decantarse por un tono más bien admonitivo y pacato. Reconoce el deber de los Estados miembros de permitir que las entidades habilitadas puedan acceder a pruebas en poder del demandado o de terceros, pero sin mucho detalle y con sujeción a ciertas condiciones (art. 18):

- Es necesario, en primer término, que la entidad habilitada aporte pruebas que cabe suponer razonablemente en su poder -v.g., porque se las han podido facilitar consumidores individuales-que acrediten, al menos indiciariamente, la procedencia de la acción de representación: la entidad solicitante, por tanto, debe acreditar una suerte de fumus boni iuris de su pretensión, que evite la utilización de esta herramienta para llevar a cabo investigaciones prospectivas o fishing expeditions.

- Es preciso, igualmente, que el solicitante identifique las pruebas a las que pretende acceder y que se hallan en poder de la contraparte o de un tercero: la finalidad de esta regla es la misma, aunque es evidente que debería bastar con exigir a la entidad solicitante que defina del modo más preciso posible el tipo de pruebas a las que pretende acceder, pues reclamar una identificación perfecta convertiría al instrumento en inoperante.

- El tribunal, además, no está obligado a acceder a la petición sin más, sino que debe someterla a un juicio de ponderación y, en todo caso, debe asegurar el respeto a las reglas sobre confidencialidad.

- Por último, y aquí radica una pieza clave, la directiva se encarga de aclarar que la potestad del tribunal de ordenar a la contraparte o a un tercero la aportación de pruebas ha de ejercerse «de conformidad con las normas procesales nacionales». Existe, pues, una remisión a la legislación procesal interna y no una genuina herramienta procesal común o armonizada: los tribunales han de poder ordenar la exhibición de pruebas -sobre esto no hay duda-, pero nada se exige en relación con la forma, el momento y los efectos, especialmente en materia de consecuencias en caso de incumplimiento - y aquí puede estar el talón de Aquiles del sistema. Si se compara con el régimen establecido para las acciones de daños en materia antitrust, parece intuirse que el legislador europeo no quiere aquí ser tan prolijo y detallado, pues las previsiones normativas son muy genéricas y quedan supeditadas a la autonomía procesal de los legisladores nacionales. Cabe apuntar, a lo sumo, que una regulación nacional que impidiera o dificultara gravemente en la práctica el acceso a fuentes de prueba podría acabar siendo considerada por el Tribunal de Justicia como lesiva del principio de efectividad -por mucho que respetara el principio de equivalencia.

76. En garantía del principio de igualdad de partes, se precisa también la existencia de un deber de exhibición a la recíproca, esto es, que las entidades habilitadas -y los terceros- estarán igualmente obligados a suministrar pruebas al profesional demandado que así lo solicite y lo justifique, en términos equivalentes a los descritos.

\section{B) Eficacia de resoluciones judiciales y administrativas previas}

77. El legislador europeo parte de la premisa de que la aplicación de las normas de consumo se puede llevar a cabo no solo por tribunales, sino también por autoridades administrativas. De hecho, la nueva directiva -al igual que las directivas de 1998 y 2009 sobre acciones de cesación- admite como posible que las acciones representativas puedan ejercerse ante autoridades administrativas -no ante tribunales- en aquellos Estados miembros que así lo contemplen. Pero no se trata solo de esto último: a las autoridades administrativas les corresponden también unas funciones regulatorias, que van acompañadas de potestades sancionadoras que pueden proyectarse sobre conductas que hayan generado daños a los consumidores (cfr., en nuestro ordenamiento, el marco general establecido por los arts. 49-52 TRDCU). Las normas tuitivas de los derechos de los consumidores, por tanto, pueden ser objeto de un public enforcement - a cargo de autoridades administrativas que actúan en calidad de reguladores- $\mathrm{y}$ de un private enforcement -a través de acciones colectivas o «de representación» ejercitadas ante tribunales 
o, en algunos Estados miembros, ante autoridades administrativas-. Estos ámbitos de actuación han tendido a desenvolverse de forma descoordinada, al menos en nuestro país. Esto determina que la actuación administrativa calificable de public enforcement no aprovecha a los perjudicados por los hechos dañosos sancionados administrativamente, cuando reclamen judicialmente la reparación de sus derechos de forma desconectada, tanto en procesos individuales como colectivos.

78. La Propuesta inicial de la Comisión apostó por trasladar a este ámbito el sistema dual regulatorio-judicial que desde hace años predomina en un sector muy cercano a este, como es el de las normas sobre defensa de la competencia. Con una clara inspiración en el artículo 9 de la Directiva sobre acciones civiles por daños antitrust ${ }^{64}$, la Comisión (art. 10 de la propuesta) planteaba otorgar eficacia vinculante sobre cualesquiera procesos posteriores a las sentencias que acuerden una orden de cesación o declaren la existencia de una infracción, pero también a las resoluciones administrativas en que se declare la existencia de dicha infracción, sin distinguir entre las resoluciones administrativas dictadas a resultas del ejercicio de una acción de representación ante un ente administrativo -allí donde resulte posible- o a consecuencia del ejercicio de la potestad regulatoria-sancionadora del ente administrativo en cuestión. Respecto de la eficacia vinculante de resoluciones judiciales, la cuestión no es especialmente polémica, pues podría verse como un supuesto de extensión a terceros de la cosa juzgada y, en todo caso, porque la limitación a la independencia judicial en que consiste la vinculación deriva de una sentencia firme emitida por un tribunal independiente. La Propuesta resultaba mucho más controvertida en la medida en que abría la puerta a otorgar eficacia vinculante a resoluciones administrativas sobre decisiones judiciales, algo siempre extraordinario y problemático, máxime en un ámbito como el del consumo, en el que -a diferencia de lo que sucede en materia antitrust- existe una fuerte descentralización de competencias administrativas, en manos de órganos cuya independencia o autonomía son discutibles. ${ }^{65}$

79. Al margen de sus ventajas e inconvenientes, lo cierto es que un sistema de vinculación como el propuesto por la Comisión se acabaría proyectando en dos planos distintos:

- Desde el punto de vista probatorio, se asegura que la existencia de una resolución firme de una autoridad competente en materia de consumo libera a la entidad demandante de la carga probatoria respecto de aquello que, sin duda, puede resultarle más difícil de acreditar, por la lejanía o la dificultad de acceso a las fuentes de prueba: la existencia de infracción que opera como título de base para la imputación de responsabilidad al demandado.

- Desde el punto de vista estratégico, se transmite un mensaje claro: parece preferible un ejercicio consecutivo de las acciones resarcitorias respecto de los procedimientos administrativos de public enforcement -no tanto respecto de acciones judiciales de cesación, pues debería caber la acumulación, según se ha visto-, aunque ello suponga esperar el tiempo necesario

${ }^{64}$ Los dos primeros apartados del artículo 9 de la Directiva 2014/104, bajo la rúbrica de «Efecto de las resoluciones nacionales», disponen lo siguiente:

«1. Los Estados miembros velarán por que se considere que la constatación de una infracción del Derecho de la competencia hecha en una resolución firme de una autoridad nacional de la competencia o de un órgano jurisdiccional competente se considere irrefutable a los efectos de una acción por daños ejercitada ante un órgano jurisdiccional nacional de conformidad con los artículos 101 o 102 del TFUE o el Derecho nacional de la competencia.

2. Los Estados miembros garantizarán que toda resolución firme contemplada en el apartado 1 y dictada en otro Estado miembro pueda ser presentada, con arreglo al Derecho nacional, ante sus órganos jurisdiccionales nacionales al menos como principio de prueba de la existencia de una infracción del Derecho de la competencia y, en su caso, que dicha resolución pueda valorarse junto con otras pruebas presentadas por las partes.»

${ }^{65}$ Cfr. F. GASCÓn INCHAUSTI, «La combinación entre actuación pública regulatoria y reclamaciones posteriores de daños: ¿una alternativa a la tormentosa relación entre acciones colectivas y acciones individuales en materia de consumo?», en $\mathrm{M}$. Cachón Cadenas, V. Pérez Daudí (dirs.), El enjuiciamiento civil y penal hoy, Atelier, Barcelona, 2019, pp. 287-307; también J. Martín Pastor, Las técnicas de reparación judicial colectiva en el proceso civil, cit., pp. 139-140; y J. LóPez SÁNCHEZ, "La Propuesta de directiva sobre acciones de representación para la protección de los intereses colectivos de los consumidores y el ámbito de representación de las entidades habilitadas para su ejercicio", cit., p. 420. 
para que concluya en firme el procedimiento administrativo sancionador, en su caso a través del agotamiento de la vía judicial.

80. Tras el paso de la Propuesta por las manos del Parlamento y del Consejo, sin embargo, las cosas han cambiado significativamente, pues se ha optado por «diluir» el alcance del precepto. Con la redacción final del artículo 15, su eficacia se ha limitado al ámbito probatorio y, además, se ha rebajado bastante. En efecto, a lo que quedan obligados los Estados miembros es a garantizar que las resoluciones firmes de un órgano jurisdiccional o una autoridad administrativa de cualquier Estado miembro que establezcan la existencia -o la inexistencia- de una infracción que perjudique los intereses colectivos de los consumidores se puedan emplear por cualquiera de las partes como prueba de la existencia $-\mathrm{o}$ de la inexistencia- de tal infracción cuando se ejerza cualquier otra acción para solicitar una reparación contra el mismo empresario por la misma infracción, de conformidad con el Derecho nacional en materia de valoración probatoria.

81. Descartar la eficacia vinculante inicialmente prevista en la Propuesta de la Comisión es algo razonable, pues la fórmula, que puede ser aceptable en materia de defensa de la competencia, no lo sería tanto en materia de consumo. Pero el resultado normativo no deja de ser extraño, en la medida en que introduce un medio probatorio nuevo en el catálogo habitual: la resolución previa de otra autoridad, judicial o administrativa, nacional o de otro Estado miembro. En efecto, las resoluciones judiciales -y, por supuesto, las administrativas-no son un medio de prueba de los hechos que en ellas mismas se declaran probados. La sentencia, como documento, únicamente prueba su propia existencia, es decir, que lo que en ella figura es realmente la fiel expresión de la decisión del tribunal -lo mismo debe valer, mutatis mutandis, para la resolución administrativa-. La sentencia, sin duda, se asienta sobre la afirmación judicial de su convicción acerca de la certeza positiva o negativa de determinados hechos; por ello, la propia sentencia recoge la valoración que el tribunal efectúa de las pruebas practicadas ante él. A partir de aquí, sostener que la sentencia hace prueba de aquello que el tribunal declara probado en ella puede verse como un «fraude de etiquetas»: es tanto como decir que el documento que acredita que un tribunal enjuició de un determinado modo unos hechos es en sí mismo prueba de la certeza de los hechos en cuestión. Lo que viene a señalar el precepto podría expresarse, en términos algo coloquiales, del siguiente modo: «Si otro tribunal o autoridad administrativa ya ha afirmado que se han producido -o que no se han producido- ciertos hechos susceptibles de calificarse como infracción, entonces me puedo fiar de él y considerar su convicción como base suficiente para sostener mi propia convicción». Lo curioso es que, apurando el razonamiento, habría que concluir que la resolución judicial o administrativa anterior ni siquiera sería prueba documental, sino que sería una suerte de prueba testifical cualificada.

82. Sea como fuere, la flexibilidad con que se ha redactado el precepto contiene el germen de su propia ineficacia, en la medida en que no se obliga a atribuir a la resolución un valor probatorio determinado - no hay valoración tasada-, sino que únicamente se permite a un tribunal sostener la existencia o la inexistencia de la infracción tomando como elemento probatorio de base la resolución previa, si ello resulta compatible con el derecho probatorio interno, que la propia directiva no obliga a modificar, sino que se erige más bien en límite a la eficacia de la directiva en este punto. Asumiendo, en todo caso, que se tratará de una prueba de valoración libre, la concreta fuerza que le atribuya un tribunal -o autoridad administrativa- a la resolución dictada previamente en otro Estado miembro dependerá de muchos factores, algunos de ellos ni siquiera fácilmente confesables, asociados a cómo el tribunal perciba la «calidad» del procedimiento en que se dictó aquella.

\section{C) Relación entre procesos conexos}

83. Uno de los numerosos problemas asociados a la protección procesal de los consumidores es la difícil articulación de las relaciones entre acciones individuales y acciones colectivas o, si se prefiere, entre los procesos en que se ejercitan dichas acciones. En efecto, el ejercicio de acciones colectivas no monopoliza la reacción jurisdiccional frente a hechos o actuaciones que lesionen los derechos o intere- 
ses de los consumidores: las acciones individuales siguen siendo posibles y, de hecho, son muy frecuentes (en parte por razones culturales -fuerte individualismo-, en parte también por la presión de cierto modelo de abogacía surgida al abrigo de la litigación financiera y bancaria asociada a la utilización de cláusulas abusivas ${ }^{66}$. En consecuencia, pueden convivir acciones colectivas y acciones individuales (entre las que se incluyen los casos en que varias acciones individuales se ejercen de forma acumulada en una misma demanda).

84. En materia de tutela frente a cláusulas abusivas, debe recordarse cómo la STJUE de 14 de abril de 2016 en el asunto Sales Sinues ${ }^{67}$ considera incompatible con el Derecho de la Unión la suspensión automática del proceso civil individual por pendencia de un proceso colectivo; al hacerlo, de manera indirecta, también está negando la posibilidad genérica de que la sentencia dictada en el proceso colectivo pueda producir efectos vinculantes sobre el proceso individual ${ }^{68}$. Se matiza, con ello, la doctrina aparentemente sentada en la STJUE de 26 de abril de 2012 en el asunto Invite $l^{69}$, que no consideraba incompatible con el ordenamiento europeo que la declaración de nulidad de una cláusula abusiva en el marco de una acción colectiva de cesación surta efectos para cualquier consumidor que haya celebrado con el profesional de que se trate un contrato al cual le sean de aplicación las mismas condiciones generales, incluso para los consumidores que no hayan sido parte en el procedimiento de cesación.

85. Debe tenerse en cuenta, por otra parte, que esta doctrina jurisprudencial se ha producido respecto de la coexistencia entre acciones colectivas de alcance cesatorio y acciones individuales en las que se pretendía algún tipo de reparación o resarcimiento (frecuentemente, la anulación de una cláusula-suelo y la devolución de cantidades cobradas indebidamente en su virtud); pero el Tribunal de Justicia no ha dicho nada acerca de las relaciones entre acciones colectivas reparatorias y acciones individuales, por la sencilla razón de que las primeras, en tanto no entre en vigor y se implemente la directiva que nos ocupa, no existen en el Derecho de la Unión, sino tan solo en algunos ordenamientos procesales nacionales.

86. Contando con estos limitados antecedentes, pero siendo consciente del problema, el legislador europeo parece haber llegado a un consenso de mínimos, que se materializa en la imposición a los Estados miembros de un mandato genérico y de un límite específico.

87. El mandato genérico es sencillo: los Estados miembros han de establecer normas que aseguren la adecuada coordinación entre las acciones representativas reguladas en la directiva, las acciones individuales interpuestas por consumidores a título particular y cualesquiera otras acciones para la protección de los intereses individuales y colectivos de los consumidores, en los términos previstos por la legislación de la Unión y nacional (considerando 48). Se establece, pues, una suerte de «obligación de resultado», no «de medios». Corresponderá a cada Estado miembro determinar cómo se organiza la coordinación, a tra-

${ }^{66}$ Cfr. M. Ortells Ramos, “Tutela judicial civil colectiva y nuevos modelos de los servicios de defensa jurídica en España”, Revista General de Derecho Procesal, Nº. 48, 2019.

${ }^{67}$ Asuntos acumulados C381/14 y C385/14, ECLI:EU:C:2016:252. Por todos, cfr. M. Aguilera Morales, "Articulación procesal de acciones individuales y colectivas en defensa de los consumidores a la luz del Derecho de la Unión”, Revista Española de Derecho Europeo, 63 (2017), pp. 111-127; R. Bellido Penadés, "Un nuevo paso hacia la tutela judicial colectiva del consumidor en el derecho de la UE (A propósito de la STJUE de 14 de abril de 2016)", en G. García-Rostán Calvín, J. SigüEnZA LóPEZ (dirs.), El proceso civil ante el reto de un nuevo panorama socioeconómico, Aranzadi, Cizur Menor, 2017, pp. 591-610; R. Bonachera Villegas, Tutela procesal de los derechos e intereses de los consumidores, Tirant lo Blanch, Valencia, 2018, pp. 84-92. Con carácter previo al pronunciamiento del Tribunal, cfr. M. CACHÓN CADENAS, N. Reynal Querol, "Concurrencia de acciones colectivas y acciones individuales para la protección de derechos e intereses de consumidores y usuarios", Revista Jurídica de Catalunya, 2015-2, pp. 141-162.

68 Apartado 42: «En este contexto, es preciso asimismo señalar que la necesidad de garantizar la coherencia entre las resoluciones judiciales no puede justificar esa falta de efectividad, ya que, tal como señaló el Abogado General en el punto 72 de sus conclusiones, la diferente naturaleza del control judicial ejercido en el marco de una acción colectiva y en el marco de una acción individual debería, en principio, evitar el riesgo de que se dicten resoluciones judiciales contradictorias.»

${ }^{69}$ Asunto C472/10, ECLI:EU:C:2012:242. 
vés, v.g., de la figura de la litispendencia, la prejudicialidad, la acumulación de procesos u otra que se diseñe ad hoc. Aunque no se diga expresamente en el texto legal, cabe asumir implícito un mandato de que los mecanismos sean realmente operativos y eficaces, para lo cual es básica la información. En relación con esto, el legislador europeo propone una herramienta que puede ser de utilidad a tal fin: la creación de un registro y de una base de datos de las acciones representativas en curso y ya resueltas, accesible para tribunales, autoridades administrativas y entidades habilitadas (art. 14). La información suministrada por el registro y la base de datos es clave para poder identificar si se están tramitando de forma simultánea o sucesiva acciones cuyos ámbitos objetivo y/o subjetivo pueden considerarse idénticos o conexos, a los efectos de hacer operativos los instrumentos procesales oportunos en cada Estado miembro.

88. Como excepción a la policy general de dejar esta cuestión en manos de la autonomía procesal de los Estados miembros la directiva considera necesario fijar e imponer una norma común para una situación determinada: los consumidores que hayan expresado explícita o tácitamente su voluntad de ser representados en una acción de representación no podrán ser representados en otras acciones de representación ni interponer una acción individual con el mismo objeto y causa y contra el mismo comerciante (art. 9.4). Existen, pues, tres prohibiciones.

(i) La primera es la de que un mismo consumidor vea defendidos sus derechos en dos procesos colectivos diferentes. Aunque el precepto es bienintencionado, su operatividad práctica puede ser muy complicada, a no ser que la información contenida en el registro y en la base de datos antes mencionados permita determinar que efectivamente es así: cabe imaginarlo como posible si se refiere a categorías bien delimitadas de consumidores, que figuren en el ámbito objetivo-subjetivo de dos acciones inscritas en el registro.

(ii) La segunda es la prohibición de que se solape la acción individual con una acción colectiva resarcitoria, cuando el consumidor se haya adherido voluntariamente a esta, de forma explícita o tácita. En la práctica, este precepto se hará eficaz cuando el empresario demandado en vía individual alegue la pendencia del proceso colectivo y la pertenencia del consumidor demandante al círculo de aquellos cuyos derechos se están viendo -o se han visto ya- representados por una acción representativa de una entidad habilitada. La regla, por otra parte, es clara cuando alude a la adhesión explícita del consumidor a la acción representativa: cabe pensar, sobre todo, en los modelos de opt-in. Puede ofrecer dudas, en cambio, a qué se refiere con la expresión tácita de la voluntad y, singularmente, si encajan aquí los consumidores que, en un modelo de opt-out, no han ejercido la facultad de desvinculación que debe habérseles ofrecido. La respuesta afirmativa es, a mi juicio, la más razonable $^{70}$, pero solo es sostenible si efectivamente el sistema asegura una comunicación efectiva de la facultad de desvincularse. Es posible, en otros términos, que el consumidor que demandó a título individual demuestre, en reacción a la petición de sobreseimiento formulada por el empresario, que no tuvo conocimiento real de la existencia del proceso colectivo y que, por tanto, no puede considerársele tácitamente adherido a aquel.

(iii) Y, como proyección en el terreno sustantivo de las anteriores, se establece una tercera prohibición: que un mismo consumidor no sea compensado más de una vez por un mismo empresario respecto del mismo hecho dañoso.

89. El complemento necesario a una regla que en cierta medida prima la acción colectiva sobre la individual -de modo análogo a como lo hace la norma, ya analizada, que establece el valor probatorio de las sentencias que declaran la existencia de una infracción- es la interrupción o suspensión de los plazos materiales de prescripción o caducidad. En concreto, la directiva (art. 16) exige a los Estados miembros que aseguren una suspensión o interrupción de los plazos de prescripción para el ejercicio de acciones individuales por parte de los consumidores, tanto durante la pendencia de un proceso colectivo

${ }^{70} \mathrm{Y}$ así lo refrenda el considerando 46. 
en que se ejerza una acción de cesación ${ }^{71}$ como durante la pendencia de un proceso en que se ejercite una acción de reparación -en este último caso, únicamente respecto de los consumidores afectados por la acción (que serán más o menos numerosos según que el modelo elegido en cada Estado miembro para desarrollar la directiva sea de opt-out o de opt-in, respectivamente).

\section{D) ¿Exigencias procedimentales?}

90. El carácter de mínimos que caracteriza a la armonización operada por la directiva se agudiza en el terreno de lo estrictamente procedimental. La directiva se limita en este punto a exigir, en sintonía con la directiva de 2009, que las acciones de cesación se tramiten «con la debida diligencia» y que, de forma más específica, los procesos en que se pretendan medidas provisionales de cesación o prohibición se tramiten de forma acelerada y sumaria (art. 17).

91. Con estas dos excepciones - por lo demás muy genéricas y poco originales-, todo queda en manos del legislador nacional, sin más límites que los deducibles del art. 47 CDFUE. ${ }^{72}$ Resulta llamativo este «lavado de manos», singularmente si se tiene en cuenta que las acciones colectivas requieren un nivel de case management superior al ordinario y un protagonismo judicial $-\mathrm{o}$, en su caso, de la autoridad administrativa- que habría justificado una mayor implicación del legislador europeo. ${ }^{73}$ En varios lugares, de hecho, la directiva otorga facultades y deberes al tribunal directamente vinculados con la mejor tutela de los derechos de los consumidores y con la evitación de una utilización abusiva de las acciones colectivas (véase, v.g., lo que ya se ha apuntado antes en relación con el carácter manifiestamente infundado de la demanda, con la existencia de conflictos de interés en la entidad habilitada que ejerce la acción, o respecto de la posible comprobación de si están pendientes otros procesos colectivos con el mismo objeto que aquel del que conoce el juez, o lo que se verá seguidamente para la homologación de transacciones); sin embargo, no se establecen deberes o límites en relación con la materialización de aquellos poderes, que habrían podido servir, entre otras cosas, para reforzar la confianza recíproca entre Estados miembros -lo que, a su vez, redundaría en una mayor eficacia práctica de preceptos como el relativo a la eficacia probatoria de resoluciones extranjeras sobre procesos nacionales.

\section{Transacciones}

92. El legislador europeo asume que las transacciones también son admisibles en el marco de los procesos colectivos, incluidos aquellos en los que se están ejerciendo pretensiones de carácter reparatorio o resarcitorio. Se trata de un enfoque correcto, pues la legitimación que se atribuye a las entidades habilitadas no lo es tan solo para el ejercicio de acciones ante autoridades judiciales o administrativas, sino más ampliamente para promover la tutela de los derechos de los consumidores, lo que incluye las soluciones transaccionales ${ }^{74}$. Debe tenerse en cuenta, no obstante, que estas transacciones se suscriben por una entidad habilitada, pero en beneficio de una pluralidad de sujetos que no han participado necesariamente ni en el proceso judicial -si es que ha llegado a incoarse-, ni en el proceso negociador.

\footnotetext{
${ }^{71}$ Recuérdese que la sentencia estimatoria de la acción de cesación valdrá como prueba de la infracción en el posterior proceso individual resarcitorio: para que al consumidor le compense la espera, es necesario que tenga asegurado que no perderá el derecho como consecuencia del transcurso del tiempo necesario para la tramitación del proceso colectivo de cesación.

${ }^{72}$ Recuérdese el considerando 12: «De conformidad con el principio de autonomía procesal, la presente Directiva no debe contener disposiciones sobre todos los aspectos de los procedimientos de las acciones de representación. Por consiguiente, corresponde a los Estados miembros establecer normas, por ejemplo sobre la admisibilidad, las pruebas o los medios de recurso aplicables a las acciones de representación.»

${ }^{73}$ Cfr. I. Tzankova, "Case Management: the stepchild of mass claim dispute resolution”, Uniform Law Review, 2014, Vol. 19-3, pp. 329-351.

${ }^{74}$ Sobre esto, con extensión, cfr. F. GaScón InCHAusti, Tutela judicial de los consumidores y transacciones colectivas, Civitas, Madrid, 2010; C. Hodges, A. STADLER (eds.), Resolving mass disputes: ADR and settlement of mass claims, Edward Elgar, Cheltenham, 2013.
} 
La clave para una adecuada regulación de este tipo de acuerdos, por tanto, se halla en asegurar que el acuerdo alcanzado es aceptable, tanto por las ventajas que aporta, como por los perjuicios que no irroga indebidamente a terceros.

93. La directiva, en todo caso, solo se ocupa de las transacciones relativas a las acciones de reparación (art. 11.1): respecto de las de cesación no resulta fácil imaginar auténticas transacciones, sino más bien allanamientos por parte del profesional demandado -al margen del resultado de una posible «consulta» previa. Y, además, solo se abordan las transacciones alcanzadas en el marco de un proceso, esto es, cuando ya se ha ejercitado la acción ante un tribunal -o autoridad administrativa- determinado. En ese contexto, se asumen como posibles dos escenarios: que las partes hayan llegado por sus medios a una transacción, que se somete a la aprobación del tribunal o autoridad administrativa; o que sea el propio tribunal -o autoridad administrativa- quien invite a las partes a tratar de llegar a un acuerdo dentro de un plazo razonable para la reparación del perjuicio sufrido por los consumidores.

94. Sea como fuere, lo importante es que se exige la revisión de la transacción por el tribunal -o por la autoridad administrativa-: sin homologación no será eficaz. Del art. 11.2 se deduce que hay ciertos motivos por los que ha de poder denegarse la aprobación de la transacción, mientras que otros son de adopción facultativa por los legisladores nacionales. El tribunal ha de estar facultado en todo caso para rechazar una transacción que sea contraria a normas nacionales imperativas o que incluya condiciones que no puedan aplicarse, teniendo en cuenta los derechos y los intereses de todas las partes, y en particular los de los consumidores afectados. Además, si así lo establece el legislador nacional al implementar la directiva, también podrá rechazarse la transacción si se considera que es injusta o desequilibrada -cabe pensar que en perjuicio de los consumidores. ${ }^{75}$

95. El rechazo a la transacción comporta la continuación del proceso (art. 11.3). Su aprobación comporta su eficacia vinculante para el empresario y para los consumidores afectados (art. 11.4 I) ${ }^{76}$. A estos efectos se prevé que los Estados miembros puedan arbitrar vías para ofrecer a los consumidores afectados por el proceso colectivo la posibilidad de aceptar o rechazar verse vinculados por las transacciones que se alcancen (art. 11.4 II): se abre así la puerta a una suerte de opt-in o de opt-out, según se establezca, que se añade a la decisión que cada legislador haya tomado acerca de cómo configurar ab initio la relación entre la acción representativa y los concretos consumidores potencialmente beneficiados por ella. ${ }^{77}$

96. El modelo resulta garantista, aunque esta necesidad de recabar un consentimiento adicional, si se establece, puede comportar dilaciones y costes suplementarios, que conviene analizar con cautela. Quizá sea preferible recabar ese consentimiento para una eventual transacción desde el inicio del proceso, de modo que: i) en los modelos de opt-in, se advierta a quien se sume a la acción de que ha de aceptar no solo la sentencia que se dicte, sino también una hipotética transacción que se apruebe por el tribunal; ii) en los modelos de opt-out, a la inversa, se advierta de que quien no se excluya del proceso podrá verse afectado no solo por la sentencia, sino también por la transacción que en su caso se apruebe. Se pueden asociar así el consentimiento para la sentencia y la transacción en un solo acto, con la reducción de costes y tiempos que ello comporta.

${ }^{75}$ En relación con las dificultades intrínsecas a este análisis cfr. S. CoROMINAS BACH, "Las futuras transacciones colectivas en la Unión Europea: ¿escrutinio judicial o principio dispositivo?", en A. MonTEsINOs GARCía (dir.), La Tutela de los Derechos e Intereses Colectivos en la Justicia del Siglo XXI, cit., pp. 303-317, en pp. 312-315.

${ }^{76}$ Para evitar dudas, no obstante, el art. 11.5 aclara que la reparación que se obtenga a través de la transacción no es incompatible con remedios adicionales previstos en la legislación europea o nacional y que no hayan quedado cubiertos por la transacción.

${ }^{77}$ Como apunta López SÁnchez, "Cabe entender que en los supuestos en que la entidad habilitada ha actuado sin "mandato", debe ofrecerse la posibilidad de aceptar el acuerdo, mientras que en los casos en que ha actuado con "mandato", de alcanzarse un acuerdo, la posibilidad que se ofrece es la de rechazarlo" "La Propuesta de directiva sobre acciones de representación para la protección de los intereses colectivos de los consumidores y el ámbito de representación de las entidades habilitadas para su ejercicio", cit., p. 421). 


\section{Financiación y costas}

97. El último de los aspectos de las acciones representativas que preocupa al legislador europeo es el relativo a su dimensión económica. Preparar, impulsar y gestionar un proceso colectivo puede ser complejo y requerir esfuerzos personales y económicos elevados: tareas como identificar a los consumidores afectados, comunicarse con ellos u obtener de ellos elementos probatorios pueden consumir recursos elevados y convertirse en factores disuasorios para el ejercicio de acciones colectivas, en perjuicio de los derechos de los consumidores. Según se vio antes, la directiva exige para poder acreditarse como entidad habilitada para el ejercicio de acciones transfronterizas no hallarse en situación de insolvencia y permite que estas entidades cuenten con algunas medidas de apoyo suplementario por parte de los Estados miembros.

98. Con esto, sin embargo, no es suficiente para regular de forma equilibrada los factores económicos que pueden incentivar o disuadir del ejercicio de pretensiones colectivas. La directiva incide en este aspecto -a efectos prácticos, el más trascendente- con una serie de reglas a través de las cuales aspira a lograr la cuadratura del círculo.

99. En primer término, la financiación del litigio por parte de terceros se somete a un control estricto, a través de las normas del art. 10, antes expuestas, que obligan a la entidad demandante a revelar sus fuentes de financiación y a detectar posibles conflictos de interés, y que pueden determinar la renuncia a la financiación o la exclusión de la legitimación de la entidad demandante. Estos controles pueden ser en cierta medida redundantes o innecesarios, si se tiene en cuenta que este tipo de procesos ofrecen muy pocos incentivos para terceros financiadores que no sean altruistas -ni tengan interés en perjudicar al demandado. En efecto, la exclusión de los daños punitivos y el estricto control sobre el destino de los fondos que se logren harán que, en la práctica, los terceros con capacidad para financiar el proceso no vean provecho o beneficio para ellos en hacerlo. ${ }^{78}$

100. En segundo término, se somete la imposición de costas al principio objetivo del vencimiento (loser pays rule) (art. 12): la entidad demandada habrá de reembolsar las costas a la entidad demandante, si la pretensión es estimada; $y$, a la inversa, la entidad demandante será condenada en costas en caso de desestimación. La regla, no obstante, abre la puerta a las condiciones y excepciones previstas en la legislación procesal nacional. Esta remisión es crucial, pues en ella ha de hallarse la respuesta, v.g., para los casos de vencimiento parcial, que pueden ser frecuentes, singularmente si se ejercen acciones resarcitorias que se concreten en la condena al pago de indemnizaciones: no será extraño que el quantum indemnizatorio concedido sea sustancialmente inferior al reclamado. El riesgo de esta remisión es que no hay solución armonizada, ni necesariamente razonable, pues en materia de condena en costas tan importante es la regla general como sus matices y excepciones.

En este terreno de las excepciones, de hecho, aporta la directiva una previsión adicional: se prohíbe expresamente que sean los consumidores afectados por la acción quienes deban asumir las costas de la entidad habilitada o del empresario (art. 12.2), aunque se abre la puerta a que los consumidores individuales deban pagar las costas provocadas por ellos de forma deliberada o negligente, en proporción al impacto de su conducta (art. 12.3).

101. Finalmente, debe recordarse la regla, antes apuntada, en que permite a los Estados miembros establecer normas en virtud de las cuales se pueda exigir a los consumidores afectados la contribu-

${ }^{78}$ Cfr., entre otros, S. MenÉtrey, «Le financement privé des actions collectives: perspective comparative et enjeux européens», Revue internationale de droit économique, 2018-4, pp. 499-515; A. STADLER, "Third Party Funding of Mass Litigation in Germany. Entrepreneurial Parties - Curse or Blessing?", en L. CAdiet, B. Hess, M. Requejo Isidro, Privatizing Dispute Resolution. Trends and Limits, Nomos, Baden-Baden, 2019, pp. 209-232; S. CorominAs BACH, "La financiación de las acciones colectivas en la Unión Europea: un análisis crítico a partir de la experiencia comparada", en T. Armenta Deu, S. Pereira PUIGVERT (coords.), Acciones colectivas (cuestiones actuales y perspectivas de futuro), cit., pp. 297-313; P. SÁnchez RiverA, "La financiación de las acciones colectivas y la third party funding. Especial referencia a la experiencia en Australia y Estados Unidos", en T. Armenta Deu, S. Pereira Puigvert (coords.), Acciones colectivas (cuestiones actuales y perspectivas de futuro), cit., pp. 315-332. 
ción al soporte económico del proceso, a través de una suma que en todo caso ha de ser «modesta» (art. 20.3) - algo que habrá de verse en cada Estado miembro y en función de lo que esté en juego en el litigio.

102. Está claro el leitmotiv de la regulación de la directiva en este punto: impedir que la litigación colectiva se convierta en una suerte de nicho para la litigación abusiva y potencialmente distorsionadora de la libre competencia, pues así es como se percibe el fenómeno de las class-actions en Estados Unidos. ${ }^{79}$ Pero, con las reglas dispuestas, cabe preguntarse lo siguiente: ¿cómo se financian los procesos colectivos, especialmente los que previsiblemente sean más costosos y complejos, esto es, aquellos que afecten a un mayor número de personas? La respuesta, como se acaba de ver, resulta de la combinación de factores múltiples: i) los recursos propios de las entidades habilitadas, teniendo en cuenta que no pueden tener ánimo de lucro, pero sí ahorros; ii) los Estados miembros, en la medida y modo en que así lo decidan, v.g. a través de ayudas o subvenciones, exenciones de tasas judiciales o vinculando a este fin las multas recaudadas por incumplimiento de acciones de cesación; iii) los propios consumidores, si se les pueden reclamar contribuciones «modestas» para adherirse a los procesos colectivos; iv) los despachos de abogados, en la medida en que los límites impuestos a nivel interno a los pactos de quota litis les permitan obtener algún margen de beneficio; v) aquellos terceros que, sin estar incursos en conflicto de interés, encuentren algún tipo de incentivo en financiar el litigio.

103. En vista del panorama, resulta difícil vaticinar el nivel de utilidad práctica de la herramienta diseñada por el legislador europeo. Existe un claro riesgo de «muerte por inanición» si la financiación se convierte realmente en un problema. Y esto, a su vez, obliga a plantearse si en realidad no hay forma de arbitrar un sistema eficaz de tutela colectiva resarcitoria que no sea manejando las mismas o, al menos, algunas variables del modelo estadounidense. ${ }^{80} \mathrm{Y}$ es que si, al final, el funcionamiento acaba dependiendo del apoyo público que reciban las entidades habilitadas, llega un momento en que puede considerarse redundante, pues cabría concluir que sería más hacedero crear una superestructura administrativa regulatoria, como el hipotético Defensor del Pueblo Europeo para las acciones de reparación colectivas cuya creación se contempla en el art. $23 .^{81}$

\section{A modo de conclusión provisional: ¿puede existir un modelo europeo de tutela colectiva, más allá del rechazo al modelo estadounidense?}

104. Esta última apreciación nos obliga a plantearnos si la nueva directiva nos coloca realmente a las puertas de un modelo europeo de tutela colectiva, ante una verdadera European way to collective redress. Todo depende, por supuesto, de qué se entienda por «modelo». A mi juicio, para que haya modelo es necesario que estén definidos los elementos esenciales del sistema, sin perjuicio de que pueda haber variantes locales -es decir, en cada Estado miembro-- El problema es que, tras analizar los elementos básicos del sistema que se establece en la directiva, resulta difícil hablar de un modelo medianamente completo cuando (i) de un lado, no se aspira a que sea la única fórmula para la tutela colectiva, sino que los ordenamientos procesales nacionales pueden disponer de otras herramientas, que resulten muy

79 S. Issacharoff, G.P. Miller, “Will Aggregate Litigation come to Europe?”, 62 Vanderbilt Law Review (2009), pp. 179 y ss., esp. pp. 197-202; R. NAGAREDA, “Aggregate Litigation Across the Atlantic and the Future of American Exceptionalism”, 62 Vanderbilt Law Review (2009), pp. 1-52.

${ }^{80}$ G. Calabresi, K. Schwartz, "The costs of class actions: allocation and collective redress in the US experience", European journal of law and economics, 2011-2, pp. 169-183; A. STADLER, "Abtretungsmodelle und gewerbliche Prozessfinanzierung bei Masseschäden", Wirtschaft und Wettbewerb, 2018-4, pp. 189-194; A. CAssone, G.B. Ramello (eds.), The Law and Economics of Class Actions in Europe: Lessons from America, Edward Elgar, Cheltenham, 2012, pp. 219-236.

${ }^{81}$ Según el precepto, a más tardar cinco años después de la aplicación de la directiva, la Comisión valorará si las acciones de representación transfronterizas pueden abordarse mejor a escala de la Unión estableciendo un Defensor del Pueblo Europeo para las acciones de reparación colectivas. A tal fin, se elaborará un informe y se enviará al Parlamento Europeo, al Consejo y al Comité Económico y Social Europeo, acompañado, en su caso, de la correspondiente propuesta. 
diferentes a la esbozada en la directiva y (ii) de otro lado, se delega la definición de muchos extremos relevantes en la autonomía procesal de los Estados miembros.

105. Con el margen de maniobra ofrecido a los Estados miembros hay muchos elementos del sistema que pueden ser muy diversos de un país a otro. No se trata solo de que no haya una mínima armonización procedimental, que permitiese identificar algunas «piezas comunes» en todas las implementaciones nacionales, como podría ser la existencia de una fase inicial ad hoc para efectuar los controles sobre la entidad legitimada y su financiación. La directiva ofrece en algunos extremos tanta libertad a los Estados miembros, que, por ejemplo, en algunos las pretensiones colectivas resarcitorias podrán interponerse ante autoridades administrativas, algo más que impensable en muchos otros. Queda igualmente indefinido algo tan básico como la opción por un modelo de inclusión o de exclusión de los consumidores en el ámbito subjetivo del proceso, a pesar del cambio radical de enfoque que subyace a uno y otro. Lo mismo sucede, por poner otro ejemplo, con el acceso a fuentes de prueba en poder de la parte contraria o de terceros, cuya eficacia dependerá de cómo lo haya diseñado cada legislador nacional.

106. Por supuesto, también son varios los extremos que sí se definen con suficiente claridad en la directiva. El principal, a mi juicio, es la férrea voluntad de controlar la legitimación activa, que sirve también como filtro para evitar un uso indebido del sistema. La directiva se decanta por una legitimación de tipo extraordinario concentrada en una lista cerrada de entidades, sobre las que está previsto un estricto control público. Se excluye, pues, cualquier manifestación de espontaneidad y cualquier margen de acción a los individuos. ${ }^{82}$

107. También es llamativo el interés del legislador europeo en definir las pretensiones susceptibles de ser ejercitadas por los cauces de esta herramienta. En esto, es notoria la voluntad de categorizar la accionabilidad, vinculándola, sobre todo en su dimensión reparatoria, al contenido de los derechos infringidos -definidos, en su gran mayoría, también por el legislador europeo.

108. Destaca asimismo, como elemento definitorio, la preocupación por someter a mayores controles los casos de dimensión transfronteriza. En esto chocan dos pulsiones enfrentadas: de un lado, el miedo de los Estados miembros a que sus sistemas económicos se vean sometidos a distorsiones foráneas a través de acciones colectivas; de otro, la idea básica de que nos hallamos en un mercado común, cuya dimensión como Espacio de Justicia se funda en el principio del mutuo reconocimiento y en la confianza recíproca.

109. En último término, debe recordarse la indefinición en cuanto a la dimensión económica de la litigación colectiva: se tiene claro lo que se quiere lograr -disuadir la litigación colectiva abusiva-, pero al hacerlo se corre el riesgo de que deje de haber suficientes incentivos como para que la herramienta se acabe utilizando en la práctica.

110. Estos elementos configuran una suerte núcleo duro de la directiva, del que se deduce en gran medida que el legislador europeo está queriendo «nadar y guardar la ropa». Es evidente que las herramientas de tutela colectiva son imprescindibles para una adecuada aplicación práctica del Derecho de consumo y, en un espacio económico y jurídico común como el europeo, era imperativo alcanzar unos estándares comunes mínimos y promover una cierta armonización -no queda más remedio que «nadar» en el mainstream de la tutela colectiva-. Pero, al mismo tiempo, se huye del modelo estadounidense de las class actions, pues se considera una fuente de litigación abusiva, potencialmente distorsionadora del modelo económico-productivo europeo ${ }^{83}$-de ahí que se quiera «guardar la ropa».

${ }^{82}$ Se plantea siempre la duda de si debe incentivarse la actuación de estos sujetos o, por el contrario, debe desconfiarse de ellos: cfr. T. Eisenberg, G. Miller, "Incentive Awards to Class Action Plaintiffs: an Empirical Study", 53 UCLA L. Rev. 1303 (2005-2006)

${ }^{83}$ Sobre la interrelación entre acciones colectivas y sistema económico cfr. D. Hensler, C. Hodges, I. Tzankova (eds.), Class actions in context: How culture, economics and politics shape collective litigation, Edward Elgar, Cheltenham, 2016. 
111. Pero nadar y guardar la ropa no es sencillo. El legislador europeo, por ejemplo, no tiene fácil prohibir los daños punitivos, pues pueden ser aceptables en los ordenamientos de algunos Estados miembros y, de hecho, se ha visto ya cómo no se han considerado incompatibles con el orden público a efectos de su reconocimiento y ejecución en determinados Estados miembros que no los admiten. ${ }^{84}$ Evitar una financiación abusiva de los litigios por parte de terceros, por otra parte, puede ser un simple brindis al sol, en la medida en que ya el sistema no ofrece de por sí los incentivos que podrían justificar una financiación legítima por terceros -o por los propios despachos de abogados. Por otro lado, la creación de fondos para recibir y gestionar las indemnizaciones, como herramienta para evitar a los consumidores el recurso a un procedimiento autónomo para cobrar -privatizando la ejecución de las sentencias- coloca el sistema europeo justamente al otro lado del Atlántico.

112. Siendo realistas, la directiva es un fiel reflejo del estado de cosas en el seno de la Unión y, en esa medida, es muestra de lo máximo que podía conseguirse de los Estados miembros en una materia considerada por estos como muy sensible y plagada de líneas rojas para unos y otros. ${ }^{85}$

${ }^{84}$ La cuestión lleva planteándose bastante tiempo: cfr., v.g., A. CAlvo CaravaCa, J. CARRASCoSa GonzÁlez, Derecho Internacional Privado, Vol. II, 16 a ed., Granada, 2016, pp. 1426-1435; también E.C. Stiefel, R. Stürner, A. StadLER, "The enforceability of excessive U.S. punitive damage awards in Germany", American Journal of Comparative Law, 1991-4, pp. 779-802. El debate más reciente se está produciendo en Italia, como apunta E. D'Alessandro, "Reconocimiento y exequátur en Italia de sentencias extranjeras que condenan al pago de daños punitivos", Revista de Derecho Privado, №. 34, 2018, pp. 313-326.

${ }^{85}$ Contrasta, por ello, con una iniciativa paralela, mucho más acabada, que se ha formulado en el marco del proyecto conjunto del European Law Institute (ELI) y de UNIDROIT para la elaboración de unas reglas comunes europeas en materia de proceso civil, las llamadas European Rules on Civil Procedure. Dentro del cuadro de reglas confeccionadas, la Parte XI (reglas 204 a 238) se dedica de forma íntegra a los procesos colectivos y ofrece un modelo más detallado, especialmente en relación con aspectos procedimentales cruciales, como el control de admisibilidad de las demandas, los poderes del juez o la eficacia de las sentencias; las reglas sobre procesos colectivos cuentan, además, con la ventaja de insertarse en el contexto más amplio de las reglas en sí, lo que otorga una mayor coherencia al sistema diseñado. Para más información sobre el Proyecto se pueden consultar las webs del ELI (https://www.europeanlawinstitute.eu/projects-publications/current-projects-feasibility-studies-and-other-activities/currentprojects/civil-procedure/) y de UNIDROIT (https://www.unidroit.org/work-in-progress/transnational-civil-procedure) (último acceso para ambas el 3 de junio de 2020). Cfr. También R. STÜRnER, "Principles of European civil procedure or a European model code? Some considerations on the joint ELI-UNIDROIT project", Uniform Law Review 19 (2014), pp. 322 y ss.; N. TROCKER, "From ALI-UNIDRoIT Principles to common European rules on access to information and evidence? A preliminary outlook and some suggestions", Uniform Law Review 19 (2014), pp. 239-291; B. Hess, "Unionsrechtliche Synthese: Mindeststandards und Verfahrensgrundsätze im acquis communautaire / Schlussfolgerungen für European Principles of Civil Procedure”, en M. Weller, C. Althammer (eds.), Mindeststandards im europäischen Zivilprozessrecht, Mohr Siebeck, Tubinga, 2020, pp. 221 y ss.; C H van Rhee, "Approximation of Civil Procedural Law in the European Union", en B. Hess, X. Kramer (eds.), From common rules to best practices in European Civil Procedure, Nomos-Hart, Baden-Baden, 2017, pp. 63-75; A. Uzelac, "Towards European Rules of Civil Procedure: Rethinking Procedural Obligations", Hungarian Journal of Legal Studies 58, No 1, pp. 3-18 (2017). E. Silvestri, "The ELI/UNIDROIT Project: A General Introduction”, en F. Gascón Inchausti, B. Hess (eds.), The Future of the European Law of Civil Procedure. Coordination or Harmonisation?, Intersentia, Cambridge, 2020, pp. 199-204. Analizando de forma específica las reglas en materia de procesos colectivos, cfr. A. StAdler, V. Smith, E. Jeuland (eds.), Collective and Mass Litigation in Europe: Model Rules for Effective Dispute Resolution, Edward Elgar, Cheltenham, 2020. 